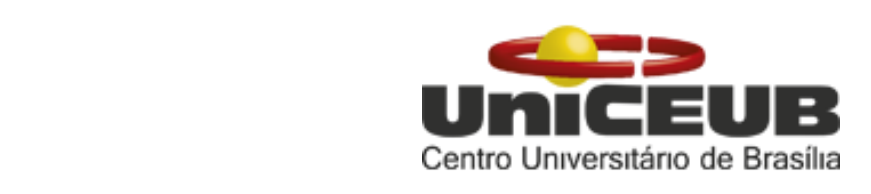

CENTRO UNIVERSITÁRIO DE BRASÍLIA - UnICEUB

FACULDADE DE CIÊNCIAS DA EDUCAÇÃO E DA SAÚDE - FACES

PROGRAMA DE INICIAÇÃO CIENTÍFICA

NATHALIA LAURIA DO NASCIMENTO

PAULA SILVA LOPES

EXTRATOS VEGETAIS COM CAPACIDADE DE INIBIÇÃO DE BIOFILME MICROBIANO

BRASÍLIA

2018 


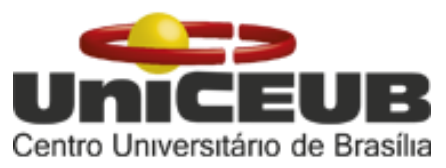

\section{NATHALIA LAURIA DO NASCIMENTO \\ PAULA SILVA LOPES}

\section{EXTRATOS VEGETAIS COM CAPACIDADE DE INIBIÇÃO DE BIOFILME MICROBIANO}

Relatório final de pesquisa de Iniciação Científica apresentado à Assessoria de Pós-Graduação e Pesquisa pela Faculdade de Ciências da Educação e da Saúde - FACES.

Orientação: Dr. Paulo Roberto Martins Queiroz.

\section{BRASÍLIA}




\title{
EXTRATOS VEGETAIS COM CAPACIDADE DE INIBIÇÃO DE BIOFILME MICROBIANO
}

\author{
Nathalia Lauria do Nascimento - UniCEUB, PIC Institucional, aluno bolsista \\ nathalia.In@sempreceub.com
}

Paula Silva Lopes - UniCEUB, PIC institucional, aluno voluntário

paula.lopes@sempreceub.com

\author{
Paulo Roberto Martins Queiroz - UniCEUB, professor orientador \\ paulo.silva@ceub.edu.br
}

Os biofilmes bacterianos são comunidades estruturadas de células microbianas aderidas umas às outras ou a superfícies imóveis ou móveis e estima-se que $65 \%$ das infecções bacterianas estão associadas a microrganismos formadores de biofilme. Devido ao aumento do número de microrganismos resistentes a antimicrobianos, novas alternativas de tratamento vêm sendo estudadas, sendo a inibição do Quorum Sensing uma estratégia promissora. O objetivo do trabalho foi identificar a atividade antimicrobiana de extratos vegetais capazes de inibir a comunicação e a formação de biofilmes microbianos. Foram utilizados óleos essenciais à base de cravo da índia (Eugenia caryophyllus), lavanda (Lavandula angustifolia), hortelã-pimenta (Mentha piperita), citronela (Cymbopogon nardus), laranja doce (Citrus aurantium dulcis), limão (Citrus limonum), eucalipto (Eucalyptus globulus), canela (Cinnamomum cassia), pimenta-rosa (Schinus terbinthifolius) e gengibre (Zingiber officinale). Os microrganismos testados foram Escherichia coli, Klebsiella pneumoniae, Pseudomonas aeruginosa, Staphylococcus aureus e Bacillus thuringiensis. Os experimentos foram feitos em placas de ELISA e por Well Difusion utilizando os extratos nas concentrações de $5 \%, 10 \%, 20 \%$ e $40 \%$. Os ensaios foram mantidos a $37{ }^{\circ} \mathrm{C}$ por $24 \mathrm{~h}$ e analisados por espectrofotometria e medição de halo, respectivamente. Os resultados indicaram que baixas concentrações de alguns extratos foram efetivas em inibir bactérias as Gram positivas e negativas utilizadas nesse estudo dentro de $24 \mathrm{~h}$ de ensaio. Além disso, algumas bactérias foram mais inibidas ( $E$. coli e $S$. aureus) do que outras indicando que os extratos exercem efeitos diferentes entre as bactérias testadas. Os resultados sugerem que os componentes presentes nos extratos vegetais podem exercem um efeito importante na formação dos biofilmes indicando uma possibilidade de uso alternativo e complementar desses compostos no controle microbiano.

Palavras-Chave: Atividade antimicrobiana. Inibição. Quorum sensing. Óleos essenciais. 
SUMÁRIO

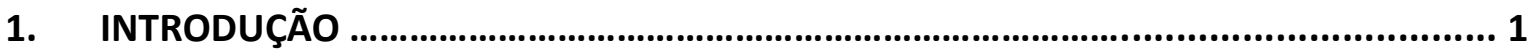

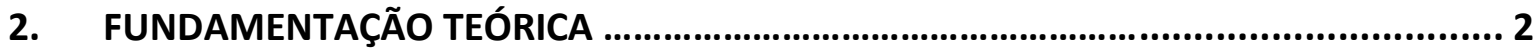

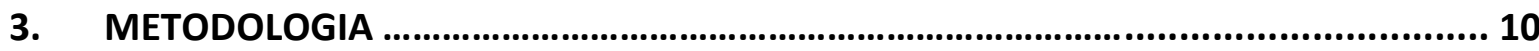

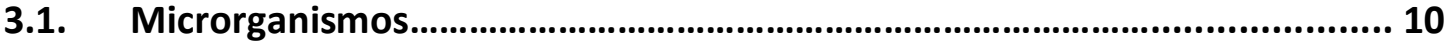

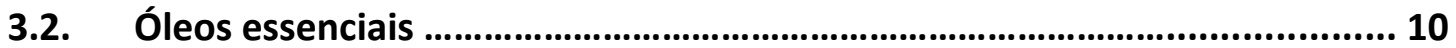

3.3. Determinação da Concentração Mínima Inibitória ........................................ 10

3.4. Identificação e Visualização da Morfologia das bactérias .............................. 11

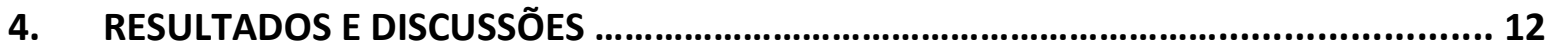

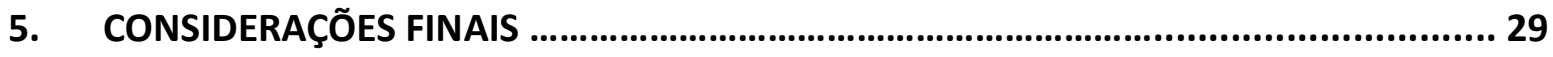

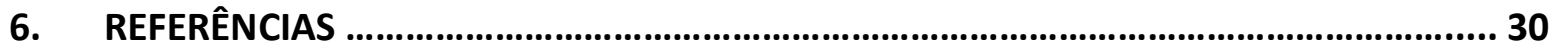




\section{INTRODUÇÃO}

A existência de qualquer organismo necessita de um elemento fundamental: a comunicação. Por meio dela foi possível que os seres humanos conseguissem evoluir, trocar informações, ideias e conhecimentos. Não diferente dos seres humanos, as bactérias também precisam da comunicação para sua sobrevivência, e este ato é conhecido como Quorum Sensing (MILLER; BLASSER, 2001).

O Quorum Sensing (QS)é responsável pela expressão dos genes em resposta à densidade celular. Neste processo são produzidas e liberadas moléculas sinalizadoras chamadas de auto indutores, que regulam o fator de virulência, esporulação, motilidade, conjugação, bioluminescência, formação do biofilme, dentre outros processos (BLASSER, 2002).

Além de comunicar-se, as bactérias organizam-se em comunidades com diferentes graus de complexidade e em superfícies diversas, constituindo um biofilme. A associação dos organismos existentes no biofilme gera relações simbióticas, proteção e sobrevivência (KASNOWSKI et al., 2010).

Os biofilmes são formados pela deposição e adesão de microrganismos em alguma superfície, biológica ou não biológica, onde se fixam, estabelecem uma matriz de exopolissacarídeos e iniciam seu crescimento (KASNOWSKI et al., 2010). Uma vez formados, os biofilmes atuam como contaminantes por meio da liberação constante de células dos microrganismos presentes no mesmo, muitos destes patogênicos e deterioradores (BOARI et al., 2009).

Biofilmes geram sérios problemas para a saúde pública devido à seleção de resistência observada por seus organismos constituintes aos agentes antimicrobianos (DONLAN, 2001). De acordo com Donlan (2001), por causa dessa resistência, microrganismos formadores de biofilmes apresentam potencial em causar infecções em seus hospedeiros.

Por ocasião da seleção microrganismos resistentes a antimicrobianos e, por geralmente, este ser o único recurso terapêutico, componentes originários de extratos vegetais vêm sendo explorados no intuito de buscar novas alternativas para tratamentos contra agente microbianos. De acordo com a Organização Mundial da Saúde (OMS), 80\% da população mundial vê o uso de plantas medicinais como principal opção terapêutica 
(TOMAZZONI, 2006) e segundo Bertini (2005), os óleos essenciais de plantas apresentam atividades antimicrobianas contra diversas bactérias, inclusive espécies resistentes a antimicrobianos e antifúngicos. O objetivo do trabalho foi identificar extratos vegetais que apresentam capacidade de inibir a comunicação (Quorum Sensing) e a formação de biofilmes microbianos.

\section{FUNDAMENTAÇÃO TEÓRICA}

Descobertas na área de microbiologia nas últimas duas décadas vêm sendo de extrema importância para o campo do controle da resistência microbiana, especialmente no que se diz respeito às perspectivas relacionadas às bactérias. Por muitos anos acreditou-se que bactérias eram seres individuais que viviam em busca de nutrientes, se multiplicavam quando lhes era favorável e atuavam de forma independente. Hoje, pesquisadores afirmam que bactérias se comportam como seres coloniais, capazes de produzir metabólitos secundários e responder a sinais gerados pelo ambiente e por outras bactérias, fato que indica a existência de comunicações entre as mesmas (KELLER; SURETTE, 2006; SOLA et al., 2012).

De acordo com Parsek; Greenberg (2005), Quorum Sensing é a expressão usada para descrever a comunicação química bacteriana. Os sinais químicos produzidos, secretados e detectados pelas bactérias podem estar relacionados à densidade celular (auto indutores) ou podem ser produzidos em diferentes estágios de crescimento. Além disso, a sinalização permite que o ambiente em que as bactérias se encontram seja monitorado e que as expressões de seus genes sejam alteradas, com a finalidade de torná-las mais adaptadas a competições com outras espécies de bactérias (JAYARAMAN; WOOD, 2008). A maioria dos processos regulados pelo Quorum Sensing não são efetivos quando apenas uma bactéria age sozinha, mas, se tornam benéficos quando um grande número de células atua em conjunto (WATERS; BASSLER, 2005).

Vários sistemas de Quorum Sensing são conhecidos, porém, apenas dois são mais descritos na literatura: 1) sistema acyl-homoserina lactone (acyl-HSL), presente em espécies Gram-negativas, sinalização peptídica, encontrada em espécies Gram-positivas, e; 2) sistema Al2, encontrado tanto em bactérias Gram-positivas como Gram-negativas (PARSEK; GREENBERG, 2003).

No mecanismo de Quorum Sensing presente em bactérias Gram-negativas, o auto indutor acyl-HSL é sintetizado por uma enzima do tipo Luxl, presente no citoplasma das 
bactérias. Esse auto indutor apresenta a capacidade de atravessar a membrana bacteriana por difusão passiva e se acumula tanto dentro quanto fora da célula, de acordo com a densidade celular. Assim que a acyl-HSL atingir sua concentração estimulatória, ela se ligará à proteína LuxR formando o complexo LuxR-HSL, o qual se acopla a promotores de genes específicos regulados pelo Quorum Sensing, ativando a transcrição, mecanismo demonstrado na figura 1 (BASSLER, 2002).

Figura 1: Mecanismo do sistema acyl-homoserina lactone (acyl-HSL) típico de bactérias Gramnegativas.

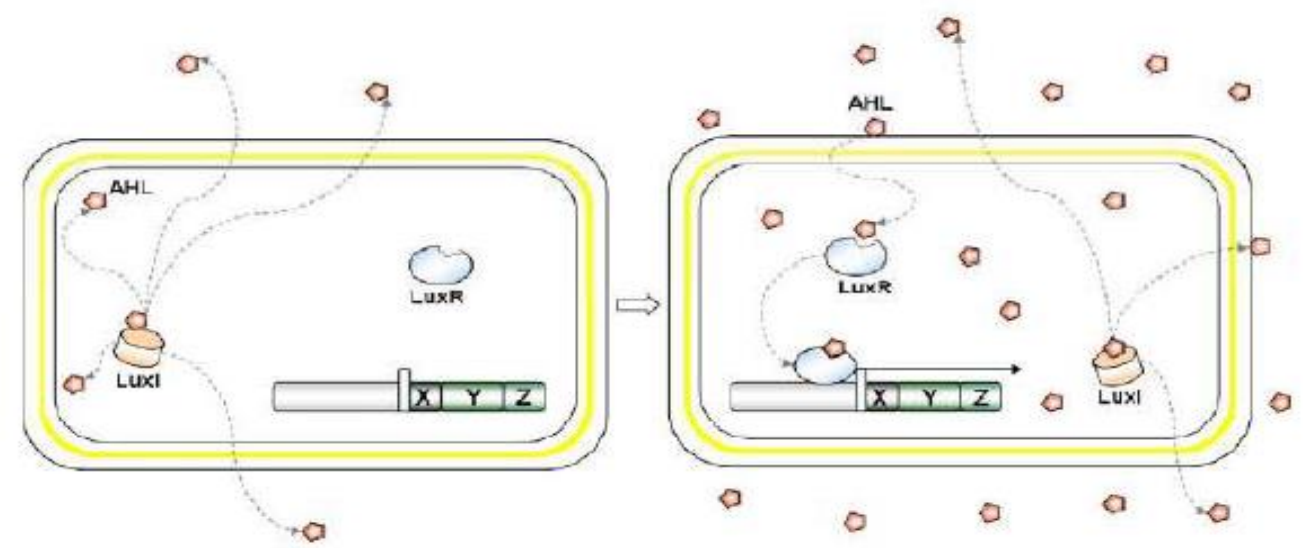

Fonte: Viana (2006).

Legenda: As letras $X, Y$ e $Z$ representam os genes alvo do sistema acyl-homoserina lactone (acyl-HSL). Luxl e LuxR são autoindutores.

O sistema baseado na sinalização peptídica, encontrado em bactérias Gram-positivas, geralmente envolve a produção de pequenos peptídeos lineares ou circulares, os quais serão traduzidos posteriormente em grandes pró-peptídeos dentro das células. Um sensor peptídico ativará, então, um mediador modulador da expressão de genes regulados por Quorum Sensing. Diferente do sistema acyl-HSL, os sinais peptídicos não são detectados dentro da célula, mas somente fora (PARSEK; GREENBERG, 2005). Diferente dos receptores citoplasmáticos do autoindutor $\mathrm{AHL}$, os receptores de oligopeptídeos estão ligados a membrana bacteriana e a transdução do sinal ocorre por meio de cascatas de fosforilação de uma proteína regulatória tendo como resposta a ligação ao DNA e regulação da transcrição dos genes alvos ( $x y z)$ (MILLER; BASSLER, 2001; VIANA, 2006). Esse mecanismo é descrito na figura 2. 
Figura 2. Mecanismo da sinalização peptídica que ocorre em bactérias Gram-positivas.

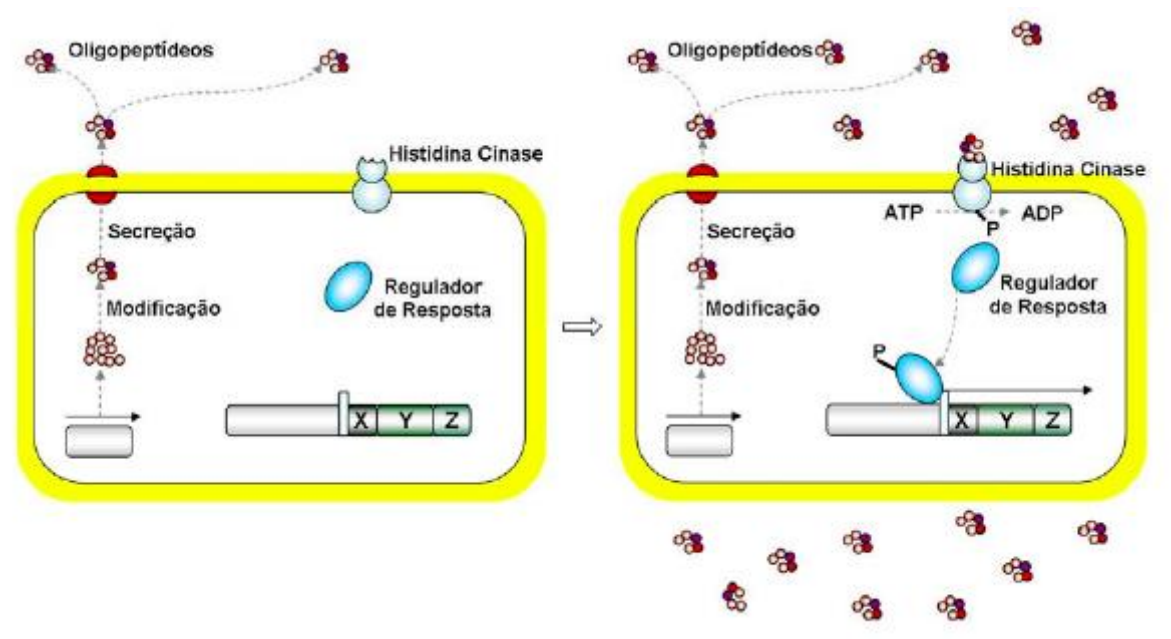

Fonte: Blasser (2002).

Segundo Federle e Blasser (2003), para que bactérias se comuniquem com outras espécies é necessário um mecanismo para o reconhecimento de moléculas sinalizadoras diferentes de suas próprias. A partir de estudos com o microrganismo Vibrio harveyi, uma bactéria luminescente, percebeu-se que esta apresenta dois autoindutores para a produção de luz, um sinal para comunicação para sua mesma espécie e outro para microrganismos diferentes. Com essa descoberta foi descrito o sistema Al-2, o qual pode ser encontrado tanto em bactérias Gram-negativas como Gram-positivas e permite a comunicação interespécies (PARSEK; GREENBERG, 2005).

A molécula auto indutora produzida pela Vibrio harveyi foi identificada como furanosil diéster. Sua síntese depende do gene $\operatorname{LuxS}$ e de seu receptor $\operatorname{LuxQ} \mathrm{Q}$ um sensor cinase de membrana (CHEN et al., 2002). A síntese dessa molécula ocorre através da S-adenosilmetionina (SAM), precursor comum para HSL e Al-2, e da interação da enzima LuxS com Sribosilhomocisteína, gerando dois produtos, a homocisteína e a Al-2 (SCHAUDER; BLASSER, 2001).

De acordo com Rumjanek e colaboradores (2004), o estudo dos autoindutores do tipo Al-2 em diversas espécies patogênicas mostrou que os sistemas de comunicação são regulados de forma complexa e alterações ambientais o influenciam. O mecanismo desse sistema funciona a partir da síntese de Al-1 e Al-2 que dependem, respectivamente, de LuxLM e LuxS e, após o aumento da concentração externa desses auto-indutores, a sinalização ocorre por meio de 
diversas reações de fosforilação/desfosforilação. Os detectores de Al-1, LuxN, e Al-2, LuxQ, contém um domínio de quinase de sensor com histidina conservada $(\mathrm{H} 1)$ e outro que regula a resposta em anexo com um aspartato conservado (D1). Os sinais de ambos os sensores são orientados para a proteína integradora LuxU, que é fosforilada em um resíduo de histidina $(\mathrm{H} 2)$. Após essas etapas, o sinal é transduzido para um resíduo de aspartato conservado (D2) que se encontra na proteína reguladora de resposta LuxO. A LuxO-fosfato é uma enzima regulatória de expressão sob a estrutura de um conjunto de genes (operon) luxCDABE. A fosforilação ocorre em um sistema sendo, $\mathrm{H} 1$ a D1 a H2 a D2. Os sensores LuxN e LuxQ também possuem atividade da fosfatase que é responsável pela desfosforilação e a inativação de LuxO. Uma proteína de ligação periplasmática, LuxP, é suposta para interagir com LuxQ e reconhecer Al-2, esse mecanismo é mostrado na figura 3.

Figura 3. Mecanismo da sinalização intraespécies (AI-2).

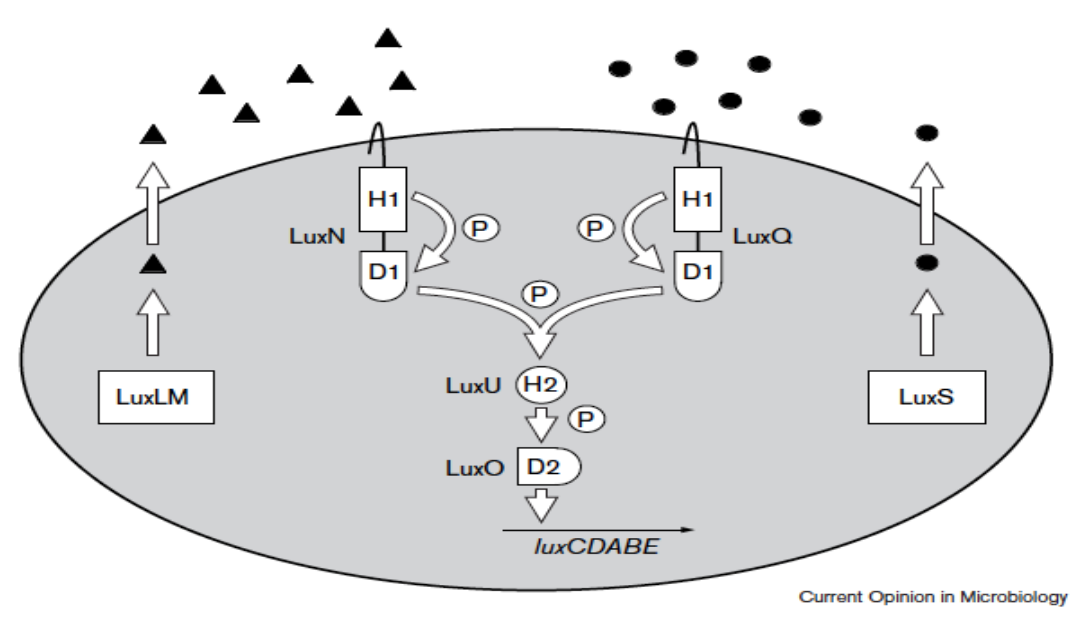

Fonte: Blasser (1999).

Grupos de pesquisadores vêm estudando a hipótese de que a comunicação química entre bactérias é responsável pelo controle da formação de comunidades bacterianas complexas, conhecidas como biofilme. Em alguns casos não há nenhuma relação entre os dois, porém, diversas espécies demonstraram que biofilmes podem sofrer influência do Quorum Sensing (PARSEK; GREENBERG, 2005).

Dentre todos os avanços na microbiologia nos últimos 50 anos, a percepção do crescimento e desenvolvimento de microrganismos em superfícies e em comunidades 
complexas foi uma das mais sutis. Durante os estudos, chegou-se à conclusão de que biofilmes não são simplesmente um emaranhado de células que se ligam às superfícies, mas sim complexos sistemas biológicos estruturados e dinâmicos (HALL-STOODLEY et al., 2004).

De acordo com Whitchurch e colaboradores (2002), biofilmes bacterianos são comunidades estruturadas de células agregadas em matrizes poliméricas hidratadas, produzidas pelas próprias bactérias, que se aderem a superfícies imóveis ou móveis. Essas superfícies se apresentam de diversas formas, desde sistemas hídricos, solo, instrumentos hospitalares, bem como, válvulas cardíacas, cateteres, feridas crônicas, tecido pulmonar e cavidades dentárias (DONLAN, 2001).

O primeiro estágio na formação do biofilme é a adesão a superfícies. Para entender este processo é necessário examinar as propriedades tanto dos substratos como da superfície celular. As características do substrato podem ter efeitos significativos na taxa de adesão do microrganismo. Em geral, quanto mais rígido e hidrofóbico, mais rápido será o desenvolvimento do biofilme no substrato. Não obstante, as características da superfície celular também são importantes como, por exemplo, a presença de flagelos, pilus, glicocálix ou fímbrias, que podem causar impactos na taxa de adesão microbiana. Este impacto é gerado, pois, uma vez introduzida à superfície, as células das bactérias necessitam superar as forças de repulsão comuns a todos os materiais, e esses anexos irão permitir que o microrganismo permaneça no local até que mecanismos de adesão permanentes sejam produzidos (DONLAN, 2001).

Figura 4: Esquema demonstrando as etapas da formação de um biofilme. Em 1, tem-se o précondicionamento da superfície; $\mathbf{2}$, transporte de células planctônicas; $\mathbf{3}$, adesão inicial em uma superfície; 4, migração de células formando microcolônias - sistema quorum sensing; 5, produção da matriz exopolimérica; 6, maturação e desenvolvimento; $\mathbf{7}$, liberação de células planctônicas.

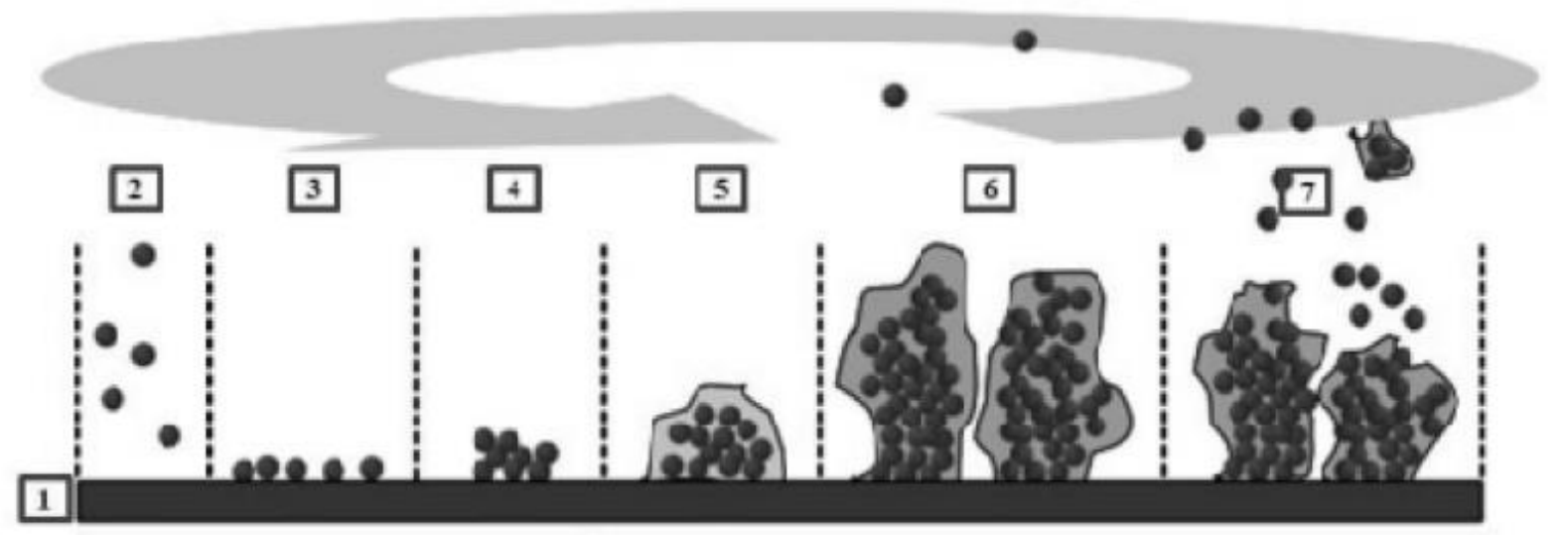

Fonte: Barros (2017). 
A maturação da comunidade do biofilme ocorre logo após a sua adesão a superfícies. A arquitetura dos biofilmes maduros pode variar de homogêneos e planos até estruturas complexas com espaços vazios e "torres" de células encapsuladas em uma matriz extracelular. A forma em que o biofilme se encontra afeta a distribuição de gradientes químicos e a potencial tolerância a antimicrobianos (PARSEK; GREENBERG, 2005).

Segundo Parsek e Greenberg (2005), estima-se que células individuais de uma variedade de espécies de bactérias são capazes de sair da formação de biofilme. Este processo é conhecido como dispersão e permite que bactérias colonizem novas superfícies e reiniciem o processo de formação do biofilme. A regulação deste processo pode ser explicada através do Quorum Sensing, pois, em situações com muitos indivíduos presentes, os recursos se tornariam limitados e o Quorum Sensing poderia servir como mediador da fuga do biofilme.

A sobrevivência do biofilme é resultado de estratégias de adaptação que são desenvolvidas com o tempo. Uma destas estratégias é a secreção extracelular de substância polimérica (EPS), uma "cola" que protege, une a população de bactérias e permite a absorção de nutrientes e oxigênio. A heterogeneidade de bactérias, presentes em um biofilme, confere também um mecanismo de proteção, pois através dela agentes antimicrobianos são menos efetivos devido à baixa taxa de crescimento (AAWC, 2008).

O National Institutes of Health (NIH) sugere que $80 \%$ das infecções em humanos são causadas por biofilmes e, geralmente, se manifestam como doenças crônicas (AAWC, 2008). Segundo Greenberg (2003), quando bactérias se encontram na forma de biofilmes, elas podem resistir às defesas do hospedeiro e apresentam tolerância a antibióticos que seriam letais caso se encontrassem sozinhas. Entre as bactérias de importância clínica que apresentam capacidade de formar biofilme se encontram Pseudomonas aeruginosa, Staphylococcus aureus, Klebsiella pneumoniae e Escherichia coli.

E. coli é uma bactéria Gram negativa encontrada no trato gastrointestinal humano ou animal. Existem sorotipos chamados de $E$. coli extra-intestinais, os quais causam infecções extraintestinais, como meningite, sepse e bacteremia. Sua capacidade de aderir e colonizar superfícies vivas ou inérteis representam um importante papel em sua virulência, servindo de estratégia de vida em ambientes hostis, como as defesas geradas pelo seu hospedeiro (CONCEIÇÃO, 2010). Os biofilmes formados por essa bactéria apresentam a capacidade de produzir hemolisina, o que irá causar inflamação no hospedeiro assim que os dispositivos 
cirúrgicos colonizados por esta bactéria entrem em contato com o organismo do paciente, dificultando ainda mais o tratamento (MILEZZI, 2012).

K. pneumoniae e $P$. aeruginosas geralmente são encontradas juntas em algumas doenças crônicas. K. pneumoniae é uma bactéria Gram-negativa, agente causador de doenças respiratórias, infecções do trato urinário e, atualmente, vem sendo a constante causa de infecções em feridas crônicas. A formação de biofilme por esta bactéria é um dos seus principais fatores de virulência utilizados para colonizar seu hospedeiro humano (CHILDERS, et al. 2013).

$P$. aeruginosa é um microrganismo capaz de causar uma variedade de infecções, desde infecções pulmonares a fibrose cística, os quais geralmente estão relacionados a contaminação de aparelhos médicos por esta bactéria. $P$. aeruginosa é capaz de manter relações antagonistas com diversas outras bactérias causadoras de infecção, incluindo S. aureus (CHILDERS et al., 2013). S. aureus é uma bactéria Gram positiva responsável por uma variedade de infecções em ambientes assistenciais e na comunidade. Possui a capacidade de formar biofilme em algumas superfícies orgânicas e inorgânicas, como mucosas e próteses, respectivamente. Atualmente mais de $90 \%$ das cepas de $S$. aureus apresentam resistência à maioria dos antimicrobianos disponíveis no mercado, como meticilina, penicilina e macrolídeos (BOSCARIOL; OUCHI; PEREIRA, 2018).

Existem outros microrganismos que formam biofilmes, porém não estão envolvidos com infecções em humanos, como é o caso do Bacillus thuringiensis, uma bactéria Gram-positiva patógena de insetos muito utilizada em biopesticidas (AUGER et al., 2009). B. thuringiensis pode causar infecções oportunistas em animais severamente imunossuprimidos (Hernandez et al., 2006).

Devido à resistência bacteriana aos antimicrobianos, está ficando cada vez mais complicado combater as infecções bacterianas. Além da resistência, segundo Tomazzoni (2006), estudiosos vêm questionando os perigos do uso abusivo de antibióticos e buscam substituí-los por compostos terapêuticos alternativos, como plantas medicinais e seus óleos essenciais.

Os óleos essenciais (OE) de plantas exercem um papel importante no tratamento de doenças infecciosas. Seus componentes atacam o sistema de Quorum Sensing das bactérias por três maneiras diferentes: interrompendo o sinal de moléculas produzidas pela enzima Luxl, degradando as moléculas sinalizadoras ou se ligando a receptores da enzima LuxR. Além disso, podem afetar a integridade dos biofilmes e torná-los mais suscetível à ação de antibióticos (KOH et al., 2013). 
A atividade antimicrobiana dos $\mathrm{OE}$ depende de suas composições químicas e da quantidade de moléculas produzidas pelas plantas. Algumas moléculas são secretadas constantemente, outras somente como forma de defesa (NAZZARO et al., 2013). Por serem hidrofóbicas e pertencerem à classe dos flavonóides, as moléculas dos OE podem afetar tanto a membrana celular quanto o citoplasma das bactérias. Ao se ligarem à membrana celular, os componentes dos $\mathrm{OE}$ impedem as atividades enzimáticas e geram efeitos tóxicos, como coagulação do citoplasma, danos a proteínas de membrana e vazamento de conteúdos celulares, o que pode explicar suas atividades antimicrobianas (NAZZARO et al., 2013; GONDIM et al., 2011).

Além de apresentar atividades antimicrobianas, alguns óleos essenciais, como os óleos à base de cravo da índia (Eugenia caryophyllus), canela (Cinnamomum cassia), lavanda (Lavandula angustifolia), hortelã-pimenta (Mentha piperita), citronela (Cymbopogon nardus), pimenta-rosa (Schinus terebinthifolius), laranja doce (Citrus aurantium dulcis), limão (Citrus limonum), eucalipto (Eucalyptus globulus) e gengibre (Zingiber officinale) apresentam propriedades antimicrobianas (CARVALHO, 2016; CARVALHO et al., 2017; SILVEIRA et al., 2012; CASTRO; 2010.) A composição química de cada óleo essencial se encontra no Quadro 1.

Quadro 1. Composição química dos óleos essenciais com propriedades antimicrobianas.

\begin{tabular}{|c|c|}
\hline Óleo Essencial & Composição Química \\
\hline Canela & Linalool, eugenol, $\alpha$-pineno, cinamaldeído. \\
\hline Citronela & $\begin{array}{c}\text { Ácido citronélico, borneol, citroneol, nerol, } \\
\text { citral, limoneno dipenteno. }\end{array}$ \\
\hline Cravo & $\begin{array}{c}\text { Eugenol, } \alpha \text {-pineno, } \beta \text {-pineno, p-cimeno, } \\
\text { limoneno, linalol. }\end{array}$ \\
\hline Eucalipto & $\begin{array}{c}1,8 \text {-cineol, } \alpha \text {-pineno, p-cimeno. } \\
\text { Gengibre }\end{array}$ \\
\hline Hortelã & $\begin{array}{c}\text { Geranial, neral, } \alpha \text {-zingibereno, ar- } \\
\text { curcumeno. }\end{array}$ \\
\hline Laranja doce & Lentol, mentona, 1,8-cineol, pulegona, \\
\hline Lavanda & 1,8 -cineol, cânfora, $\alpha$-pineno, silvestreno, \\
\hline
\end{tabular}




\begin{tabular}{|c|c|}
\hline & fenchona. \\
\hline Limão & Limoneno, $\beta$-pineno, citral, $\gamma$-terpineno. \\
\hline Pimenta rosa & $\begin{array}{c}\beta \text {-felandreno, } \delta \text {-3-careno, silvestreno, } \alpha \text { - } \\
\text { pineno. }\end{array}$ \\
\hline
\end{tabular}

Fonte: CARVALHO (2016); CARVALHO et al. (2017); SILVEIRA et al. (2012); CASTRO (2010).

\section{METODOLOGIA}

\subsection{Microrganismos}

Foram testados os microrganismos $P$. aeruginosa, S. aureus, K. pneumoniae, E. coli e B. thuringiensis. Todas as bactérias foram armazenadas sob refrigeração e, 24 horas antes dos experimentos foram repicadas em ágar CPS e incubados a $37^{\circ} \mathrm{C} . P$. aeruginosa, S. aureus, $K$. pneumoniae, E. coli foram obtidas da Coleção UFPEDA, do Departamento de Antibióticos, do Centro de Ciências Biológicas da Universidade Federal de Pernambuco. B. thuringiensis foi obtido da coleção de bactérias entomopatogênicas da Embrapa Recursos Genéticos e Biotecnologia.

\section{2. Óleos essenciais}

Foram testados óleos essenciais de laranja doce, limão, citronela, eucalipto globulus, cravo, lavanda, hortelã disponíveis no mercado da marca BioEssência, o óleo essencial de pimenta-rosa da marca Terra Flor, o óleo essencial a base de canela da marca By Samia e o óleo essencial de gengibre da marca Arte dos Aromas.

\subsection{Determinação da atividade microbiana dos extratos vegetais}

Para a determinação da concentração mínima inibitória foram utilizadas placas de Ágar Mueller-Hinton, onde orifícios com $1 \mathrm{~cm}$ de diâmetro e $4 \mathrm{~mm}$ de profundidade foram feitos e, em seguida, as bactérias foram semeadas por toda a placa com o auxílio de swabs estéreis. Nos orifícios, foram colocados os extratos que foram obtidos anteriormente com concentrações variando de $2 \%, 5 \%, 10 \%, 20 \%$ e $40 \%$. As placas foram incubadas a $37{ }^{\circ} \mathrm{C}$ por 48 h. Após esse período, foi verificada a presença de halos ao redor dos orifícios e medidos os diâmetros dos halos com auxílio de um paquímetro ou régua (BERTINI et al., 2005). Para 
chegar ao resultado, foram realizadas três medidas diferentes e realizada uma média entre as três medições.

Além da determinação da CMI em placas de Ágar Mueller-Hinton, foi realizado também o teste de microdiluição em caldo em placas de ELISA. Para cada óleo foi utilizada uma placa de Elisa e quatro bactérias em triplicata. Foram feitas suspensões das bactérias ( $E$. coli, K. pneumoniae, P. aeruginosa e $S$. aureus) em meio $\mathrm{BHI}$ e ajustada a 0,5 na escala de McFarland. Nos orifícios 1A a 12A das placas de Elisa foram colocadas soluções controle, contendo 100 uL de água destilada e 100 uL da bactéria analisada. Nos orifícios 1B a 12B foram colocados 95 uL de água destilada, extrato na concentração de 2,5\% (5 uL) e 100 uL de bactéria. Nos orifícios $1 \mathrm{C}$ a $12 \mathrm{C}$ foram colocados 90 uL de água destilada, extrato na concentração de $5 \%$ (10 uL) e 100 uL de bactéria. Nos orifícios 1D a 12D foram colocados 80 uL de água destilada, extrato na concentração de 10\% (20 uL) e 100 uL de bactéria. Nos orifícios $1 \mathrm{E}$ a $12 \mathrm{E}$ foram colocados 60 uL de água destilada, extrato na concentração de $20 \%$ (40 uL) e $100 \mathrm{uL}$ de bactéria. Nos orifícios $1 \mathrm{~F}$ a $12 \mathrm{~F}$ foram colocados $20 \mathrm{uL}$ de água destilada, extrato na concentração de 10\% (80 uL) e 100 uL de bactéria. Após a inoculação as placas foram incubadas em $37^{\circ} \mathrm{C}$ por $24 \mathrm{~h}$.

A bactéria $B$. thuringiensis teve a mesma metodologia, porém a placa de ELISA foi incubada por $24 \mathrm{~h}$ a $28^{\circ} \mathrm{C}$.

\subsection{Detecção do biofilme}

Ao final de cada tratamento com os extratos vegetais foi realizada a coloração de Gram. Foram utilizadas placas de ELISA para realizar a identificação da morfologia das bactérias utilizadas. Primeiramente os poços foram lavados 300 uL de água destilada. Após a lavagem as bactérias foram fixadas à placa pela adição de 150 uL de metanol por 20 min. Após os 20 minutos o metanol foi retirado e esperou-se a placa secar em temperatura ambiente. Após a secagem realizou-se a coloração adicionando-se 150 uL de cristal violeta por 15 min em temperatura ambiente. $\mathrm{O}$ cristal violeta foi retirado com pipeta e em seguida procedeu-se às lavagens da placa em água destilada ou de torneira até todo o corante ser removido. Após as placas secarem, adicionou-se 150 uL de etanol 95\% por 30 min sem agitação e foi realizada a leitura a $570 \mathrm{~nm}$. 


\section{RESULTADOS E DISCUSSÃO}

Em geral, os OE's são capazes de inibir o crescimento bacteriano e, também, a produção de metabólitos tóxicos bacterianos. As atividades antimicrobianas dos óleos essenciais não estão associadas a apenas um único mecanismo, mas sim a uma cascata de reações que envolvem toda a célula da bactéria, propriedade conhecida como versatilidade dos óleos essenciais. Além disso, os alvos dos óleos essenciais nas células bacterianas dependem da composição química dos mesmos, sendo assim, diferentes óleos essenciais apresentam efeitos diferentes sobre as bactérias (NAZZARRO et al., 2013).

Para Burt (2004), os principais alvos de ação dos óleos são: (1) interferência na bicamada fosfolipídica da membrana celular, o que levaria a desestabilização tanto da membrana celular, quanto da mitocôndria, o que levaria a uma mudança de potencial e, consequentemente, aumentando a permeabilidade celular, levando a célula a sofrer lise; (2) interferir nos sistemas de produção de enzimas, principalmente aqueles que estão envolvidos na produção de ATP e na síntese de elementos estruturais e; (3) a destruição do material genético.

A metodologia utilizada para estabelecer o grau de inibição do crescimento microbiano dos óleos essenciais ocorre através da difusão em ágar e o potencial é determinado pelo tamanho da zona de inibição que é formada em volta da cavidade ou do disco (KALEMBA; KUNICKA, 2003). Apesar desta metodologia ser utilizada com uma alta frequência, alguns autores a criticam, pois sugere-se que as propriedades hidrofóbicas dos óleos essenciais não permitem a difusão uniforme de suas substâncias através do meio de cultura. Porém, em um trabalho realizado por Inoue e colaboradores (2006) foi demonstrado que a volatilidade dos OE's contribui para a formação dos halos de inibição, corroborando a ideia de que a metodologia de difusão em ágar é válida na determinação de atividade antimicrobiana, visto que a volatilidade elevada dos OE's compensa a baixa capacidade de difusão dos mesmos.

Observa-se nos gráficos 1 e 2 que os óleos essenciais a base de laranja doce e eucalipto apresentaram propriedades antibacterianas frente a todas as bactérias analisadas. $\mathrm{O}$ óleo essencial a base de laranja doce apresentou os maiores halos de inibição dentre todos os óleos, e $B$. thuringiensis foi mais susceptível a este óleo do que as demais bactérias. O mesmo resultado pôde ser observado em um estudo realizado por Dorman e Deans (2002), onde as 
bactérias Gram positivas eram mais suscetíveis aos óleos essenciais que as Gram negativas, fato que pode ser explicado devido a existência de uma membrana exterior a parede celular destes microrganismos, impedindo a completa difusão de compostos hidrofóbicos. Este resultado pôde ser observado também na presente pesquisa, visto que as bactérias $E$. coli e K. pneumoniae apresentaram os menores halos de inibição comparados às demais.

Gráfico 1: Concentração mínima inibitória do óleo essencial de laranja doce.

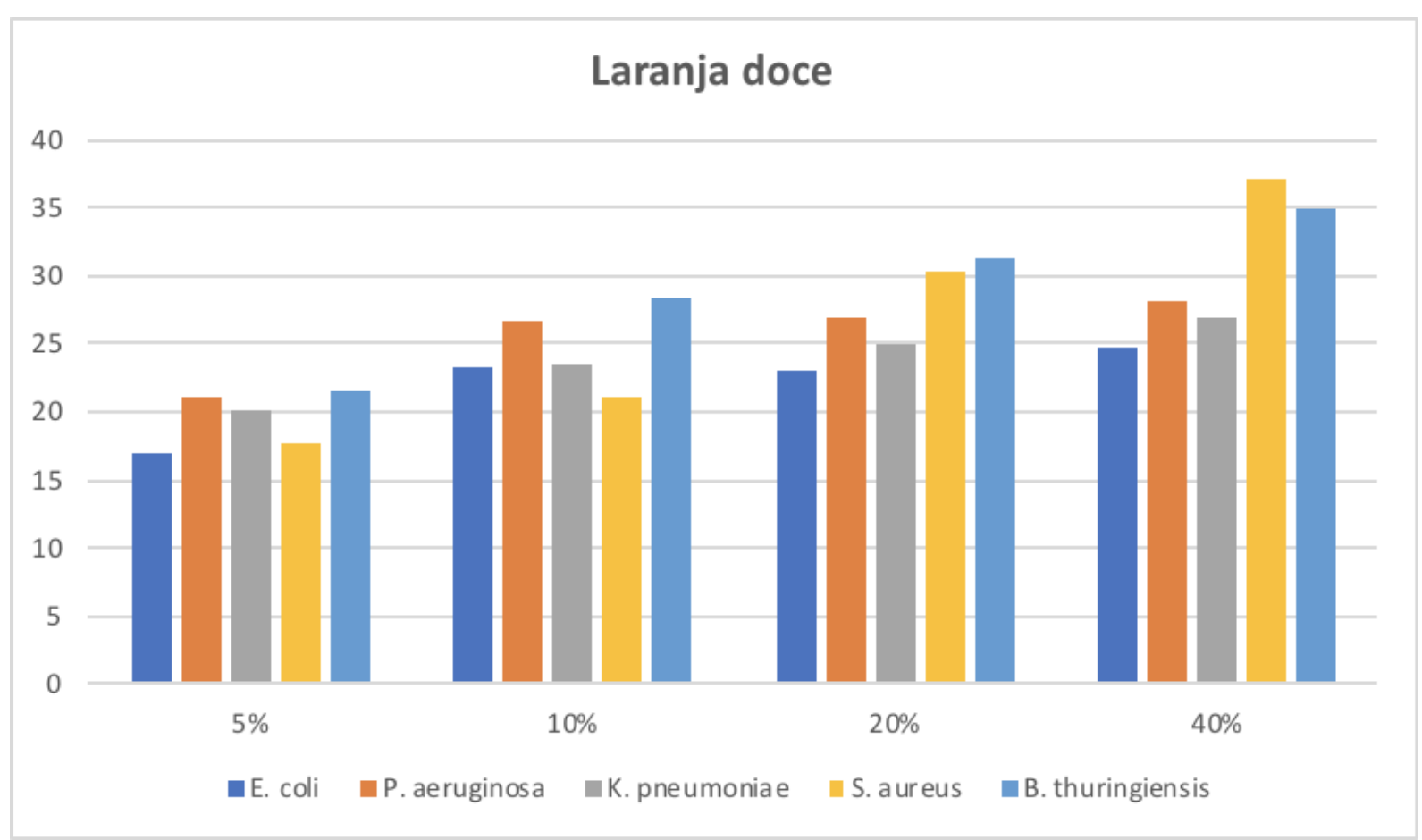


Gráfico 2: Concentração mínima inibitória do óleo essencial de eucalipto.

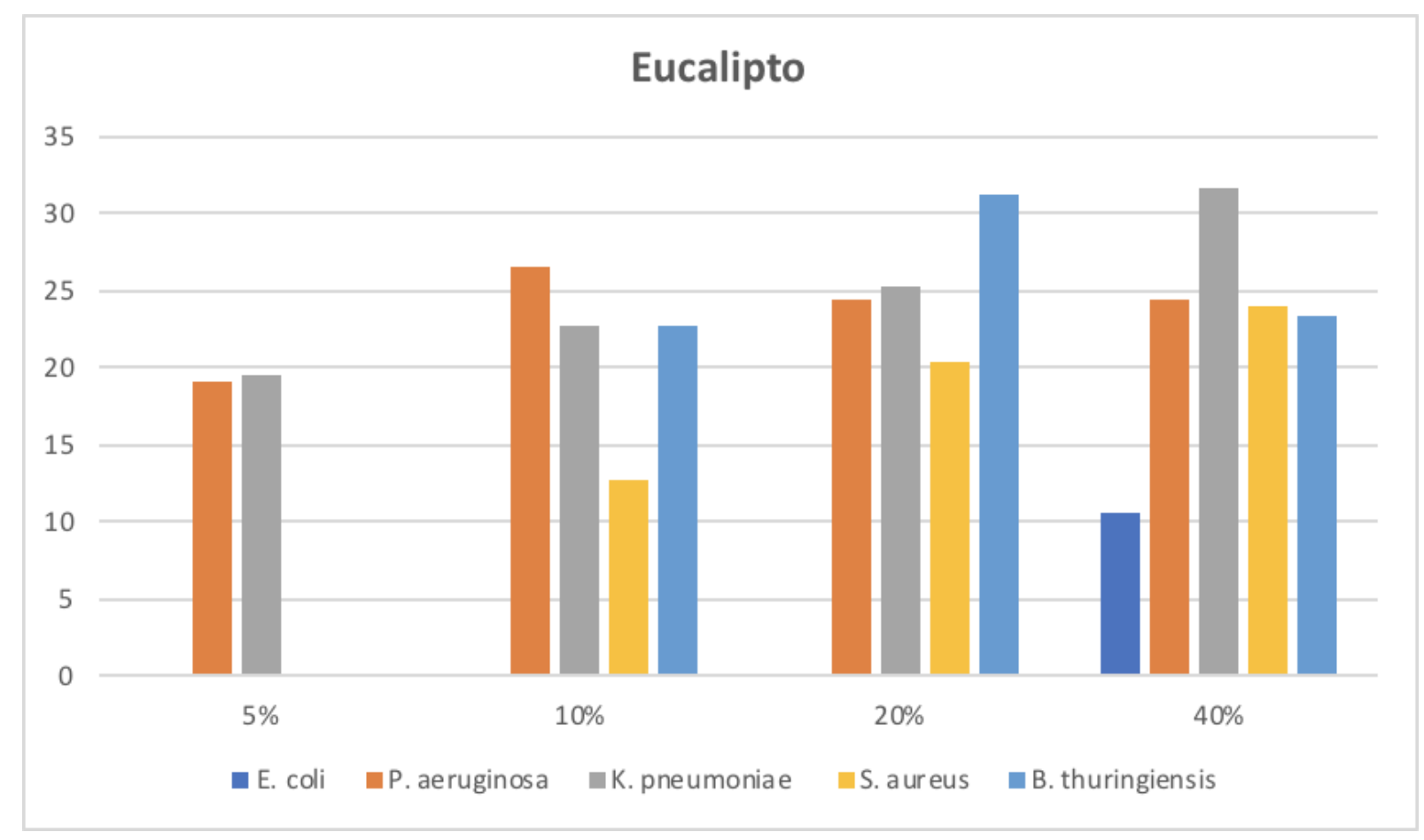

De acordo com a Tabela 1, é possível identificar a concentração mínima inibitória de cada óleo quando associado ao S. aureus, o óleo essencial mais eficaz e aquele que não apresenta propriedades bacteriostáticas frente a esta bactéria. É possível perceber que em alguns óleos essenciais, como o de limão, S. aureus só é inibido a concentrações maiores deste óleo. O óleo de limão (Citrus limon L.) possui como principais constituintes o limoneno e citral, os quais apresentam atividade antibacteriana sobre as bactérias $E$. coli e $S$. aureus constatada (MISHARINA; SAMUSENKO, 2008; SCHUCK et al., 2001). 
Tabela 1: Atividade antimicrobiana em placas de Ágar Mueller-Hinton contendo os óleos essenciais frente a bactéria S. aureus.

\begin{tabular}{|c|c|c|c|c|}
\hline Óleos essenciais & \multicolumn{4}{|c|}{ Staphylococcus aureus } \\
\hline Concentrações & $5 \%$ & $10 \%$ & $20 \%$ & $40 \%$ \\
\hline Canela & $26,1 \mathrm{~mm}$ & $30,6 \mathrm{~mm}$ & $30,0 \mathrm{~mm}$ & $33,0 \mathrm{~mm}$ \\
\hline Citronela & NI & NI & NI & NI \\
\hline Cravo & $24,3 \mathrm{~mm}$ & $24,3 \mathrm{~mm}$ & $27,3 \mathrm{~mm}$ & $29,6 \mathrm{~mm}$ \\
\hline Eucalipto & NI & $12,6 \mathrm{~mm}$ & $20,3 \mathrm{~mm}$ & $24,0 \mathrm{~mm}$ \\
\hline Gengibre & NI & $13,0 \mathrm{~mm}$ & $13,0 \mathrm{~mm}$ & $15,3 \mathrm{~mm}$ \\
\hline Hortelã-menta & NI & NI & NI & NI \\
\hline Lavanda & NI & NI & NI & NI \\
\hline Laranja & $17,6 \mathrm{~mm}$ & $21,0 \mathrm{~mm}$ & $30,3 \mathrm{~mm}$ & $37,0 \mathrm{~mm}$ \\
\hline Limão & NI & $9,6 \mathrm{~mm}$ & $20,0 \mathrm{~mm}$ & $26,6 \mathrm{~mm}$ \\
\hline Pimenta rosa & NI & NI & NI & NI \\
\hline
\end{tabular}

Legenda: NI: não inibiu.

Nas Tabelas 2, 3 e 4 é possível observar que os óleos não são muito eficazes em concentrações menores frente a bactérias Gram negativas como acontece nas bactérias Gram positivas. 
Tabela 2: Atividade antimicrobiana em placas de Ágar Mueller-Hinton contendo os óleos essenciais sob a bactéria $P$. aeruginosa.

\begin{tabular}{|c|c|c|c|c|}
\hline Óleos essenciais & \multicolumn{4}{|c|}{ Pseudomonas aeruginosa } \\
\hline Concentrações & $5 \%$ & $10 \%$ & $20 \%$ & $40 \%$ \\
\hline Canela & NI & $13,0 \mathrm{~mm}$ & $16,0 \mathrm{~mm}$ & $21,0 \mathrm{~mm}$ \\
\hline Citronela & NI & NI & NI & NI \\
\hline Cravo & $18,0 \mathrm{~mm}$ & $20,0 \mathrm{~mm}$ & $21,0 \mathrm{~mm}$ & $21,0 \mathrm{~mm}$ \\
\hline Eucalipto & $19,0 \mathrm{~mm}$ & $26,6 \mathrm{~mm}$ & $24,3 \mathrm{~mm}$ & $24,3 \mathrm{~mm}$ \\
\hline Gengibre & NI & NI & NI & NI \\
\hline Hortelã-menta & NI & NI & NI & NI \\
\hline Lavanda & NI & NI & NI & NI \\
\hline Laranja & $21,0 \mathrm{~mm}$ & $26,6 \mathrm{~mm}$ & $27,0 \mathrm{~mm}$ & $28,0 \mathrm{~mm}$ \\
\hline Limão & NC & NC & NC & NC \\
\hline Pimenta rosa & NC & NC & NC & NC \\
\hline
\end{tabular}

Legenda: NI: não inibiu; NC: não houve crescimento. 
Tabela 3: Atividade antimicrobiana em placas de Ágar Mueller-Hinton contendo os óleos essenciais sob a bactéria $E$. coli.

\begin{tabular}{|c|c|c|c|c|}
\hline Óleos essenciais & \multicolumn{4}{|c|}{ Escherichia coli } \\
\hline Concentrações & $5 \%$ & $10 \%$ & $20 \%$ & $40 \%$ \\
\hline Canela & $16,6 \mathrm{~mm}$ & $46,0 \mathrm{~mm}$ & $30,0 \mathrm{~mm}$ & $33,0 \mathrm{~mm}$ \\
\hline Citronela & NI & NI & NI & NI \\
\hline Cravo & NI & $15,6 \mathrm{~mm}$ & $21,3 \mathrm{~mm}$ & $27,3 \mathrm{~mm}$ \\
\hline Eucalipto & NI & NI & NI & $10,5 \mathrm{~mm}$ \\
\hline Gengibre & NI & NI & NI & NI \\
\hline Hortelã-menta & NI & NI & NI & NI \\
\hline Lavanda & NI & $14,3 \mathrm{~mm}$ & $22,6 \mathrm{~mm}$ & $24,0 \mathrm{~mm}$ \\
\hline Laranja & $17,0 \mathrm{~mm}$ & $22,3 \mathrm{~mm}$ & $23,0 \mathrm{~mm}$ & $24,6 \mathrm{~mm}$ \\
\hline Limão & NI & NI & $\mathrm{NI}$ & $23,0 \mathrm{~mm}$ \\
\hline Pimenta rosa & NI & NI & NI & NI \\
\hline
\end{tabular}

Legenda: NI: não inibiu. 
Tabela 4: Atividade antimicrobiana em placas de Ágar Mueller-Hinton contendo os óleos essenciais frente a bactéria K. pneumoniae.

\begin{tabular}{|c|c|c|c|c|}
\hline Óleos essenciais & \multicolumn{4}{|c|}{ Klebisiella pneumoniae } \\
\hline Concentrações & $5 \%$ & $10 \%$ & $20 \%$ & $40 \%$ \\
\hline Canela & $15,0 \mathrm{~mm}$ & $15,3 \mathrm{~mm}$ & $18,0 \mathrm{~mm}$ & $23,3 \mathrm{~mm}$ \\
\hline Citronela & NC & NC & NC & NC \\
\hline Cravo & $18,6 \mathrm{~mm}$ & $20,0 \mathrm{~mm}$ & $21,3 \mathrm{~mm}$ & $21,3 \mathrm{~mm}$ \\
\hline Eucalipto & $19,6 \mathrm{~mm}$ & $22,6 \mathrm{~mm}$ & $25,3 \mathrm{~mm}$ & $31,6 \mathrm{~mm}$ \\
\hline Gengibre & NI & NI & NI & NI \\
\hline Hortelã-menta & NI & NI & NI & NI \\
\hline Lavanda & $19,6 \mathrm{~mm}$ & $19,3 \mathrm{~mm}$ & $23,6 \mathrm{~mm}$ & $21,0 \mathrm{~mm}$ \\
\hline Laranja & $20,0 \mathrm{~mm}$ & $23,6 \mathrm{~mm}$ & $25,0 \mathrm{~mm}$ & $27,0 \mathrm{~mm}$ \\
\hline Limão & NC & NC & NC & NC \\
\hline Pimenta rosa & NI & NI & NI & NI \\
\hline
\end{tabular}

Legenda: NI: não inibiu; NC: não houve crescimento.

É importante salientar que durante a realização dos experimentos a bactéria $B$. thuringiensis acabou não apresentando um comportamento uniforme de crescimento, impedindo o crescimento da mesma em diversos ensaios com os óleos essenciais e impossibilitando a avaliação completa da bactéria, como pode ser observado na Tabela 5. 
Tabela 5: Atividade antimicrobiana em placas de Ágar Mueller-Hinton contendo os óleos essenciais frente a bactéria $B$. thuringiensis.

\begin{tabular}{|c|c|c|c|c|}
\hline Óleos essenciais & \multicolumn{4}{|c|}{ Bacillus thuringiensis } \\
\hline Concentrações & $5 \%$ & $10 \%$ & $20 \%$ & $40 \%$ \\
\hline Canela & NC & NC & NC & NC \\
\hline Citronela & NC & NC & NC & NC \\
\hline Cravo & NC & NC & NC & NC \\
\hline Eucalipto & NI & $22,6 \mathrm{~mm}$ & $31,3 \mathrm{~mm}$ & $23,3 \mathrm{~mm}$ \\
\hline Gengibre & NC & NC & NC & NC \\
\hline Hortelã-menta & NC & NC & NC & NC \\
\hline Lavanda & NI & NI & NI & NI \\
\hline Laranja & $21,6 \mathrm{~mm}$ & $28,3 \mathrm{~mm}$ & $31,3 \mathrm{~mm}$ & $35,0 \mathrm{~mm}$ \\
\hline Limão & $15,3 \mathrm{~mm}$ & $21,3 \mathrm{~mm}$ & $16,3 \mathrm{~mm}$ & $19,6 \mathrm{~mm}$ \\
\hline Pimenta rosa & NC & NC & NC & NC \\
\hline
\end{tabular}

Legenda: NI: não inibiu; NC: não houve crescimento.

Não foram encontrados na literatura critérios que avaliem a eficiência da ação antimicrobiana de extratos de óleos essenciais. Para Inoue (2006), zonas de inibição bacterianas menores que $1 \mathrm{~mm}$ não apresentam atividade antimicrobiana, atividades antimicrobianas pequenas devem conter zonas de inibição entre 2-3 mm e atividade antimicrobiana moderada deve conter zonas de inibição entre 6-9 mm. Segundo Mothana e Lindequist (2005), para um extrato ter sua ação classificada como moderadamente ativa, os 
halos de inibição devem ter de 8 a $13 \mathrm{~mm}$, e para serem considerados como muito ativos os halos devem ser maiores que $14 \mathrm{~mm}$.

Figura 1: Halos de inibição da cepa de S. aureus frente ao óleo essencial de laranja em ágar Mueller Hinton.
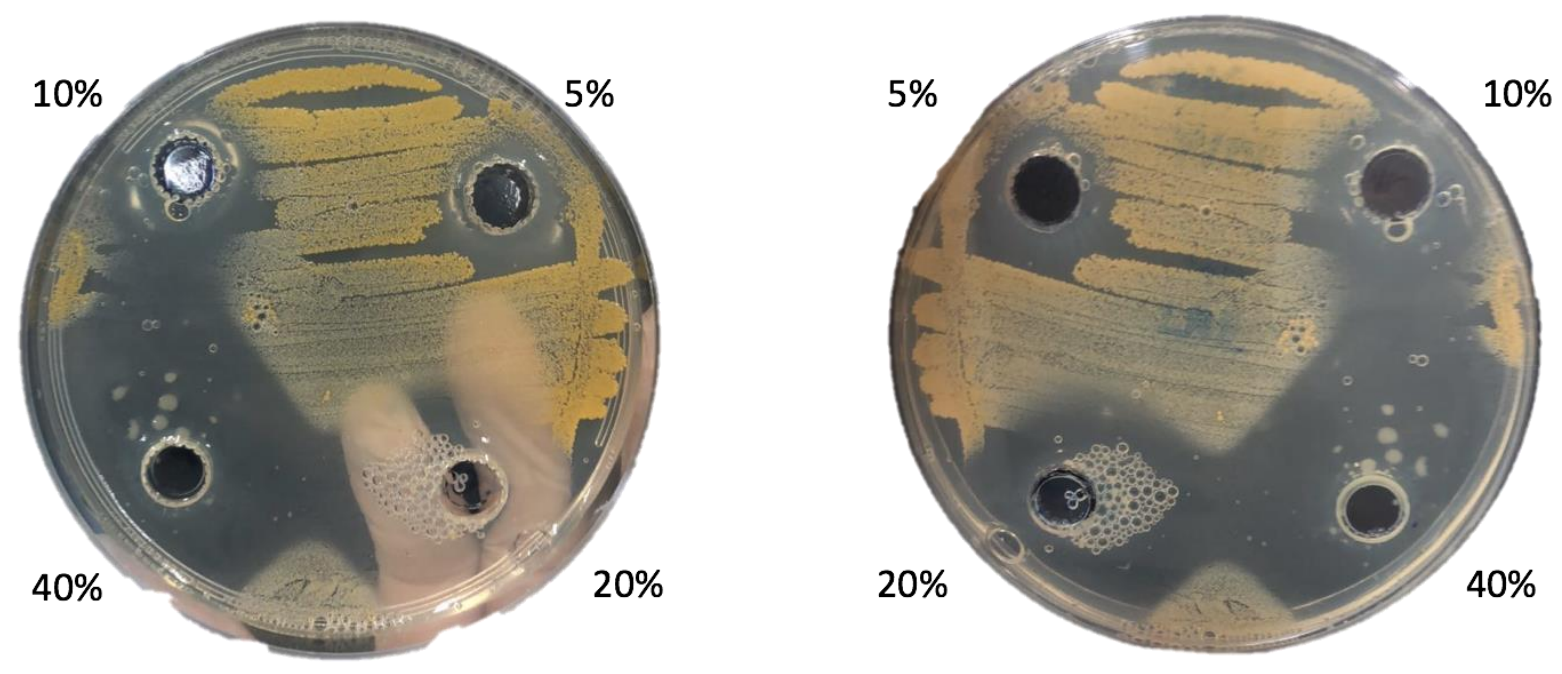

Figura 2: Halos de inibição da cepa de $P$. aeruginosa frente ao óleo essencial de laranja em ágar Mueller Hinton.
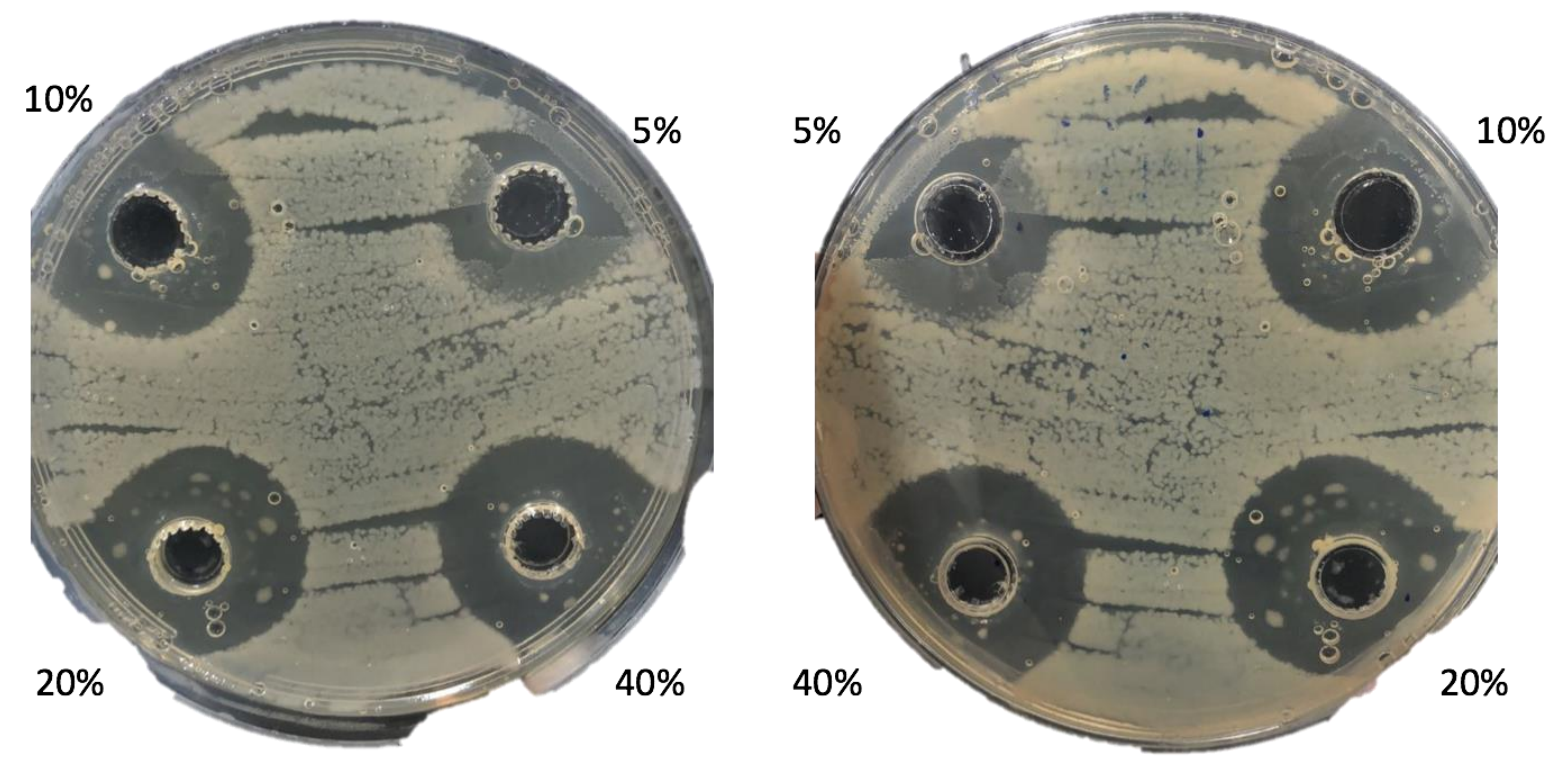
Figura 3: Halos de inibição da cepa de $E$. coli frente ao óleo essencial de laranja em ágar Mueller Hinton.
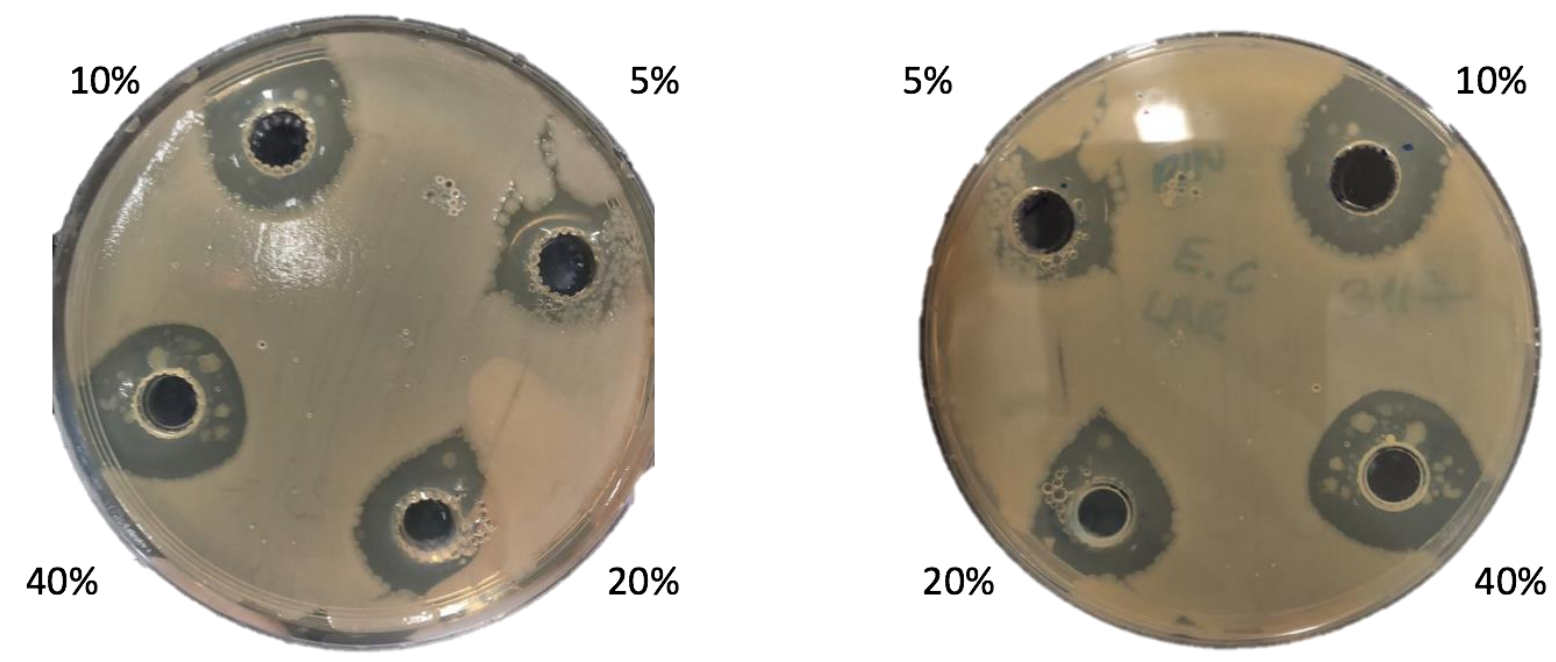

Figura 4: Halos de inibição da cepa de $K$. pneumoniae frente ao óleo essencial de laranja em ágar Mueller Hinton.

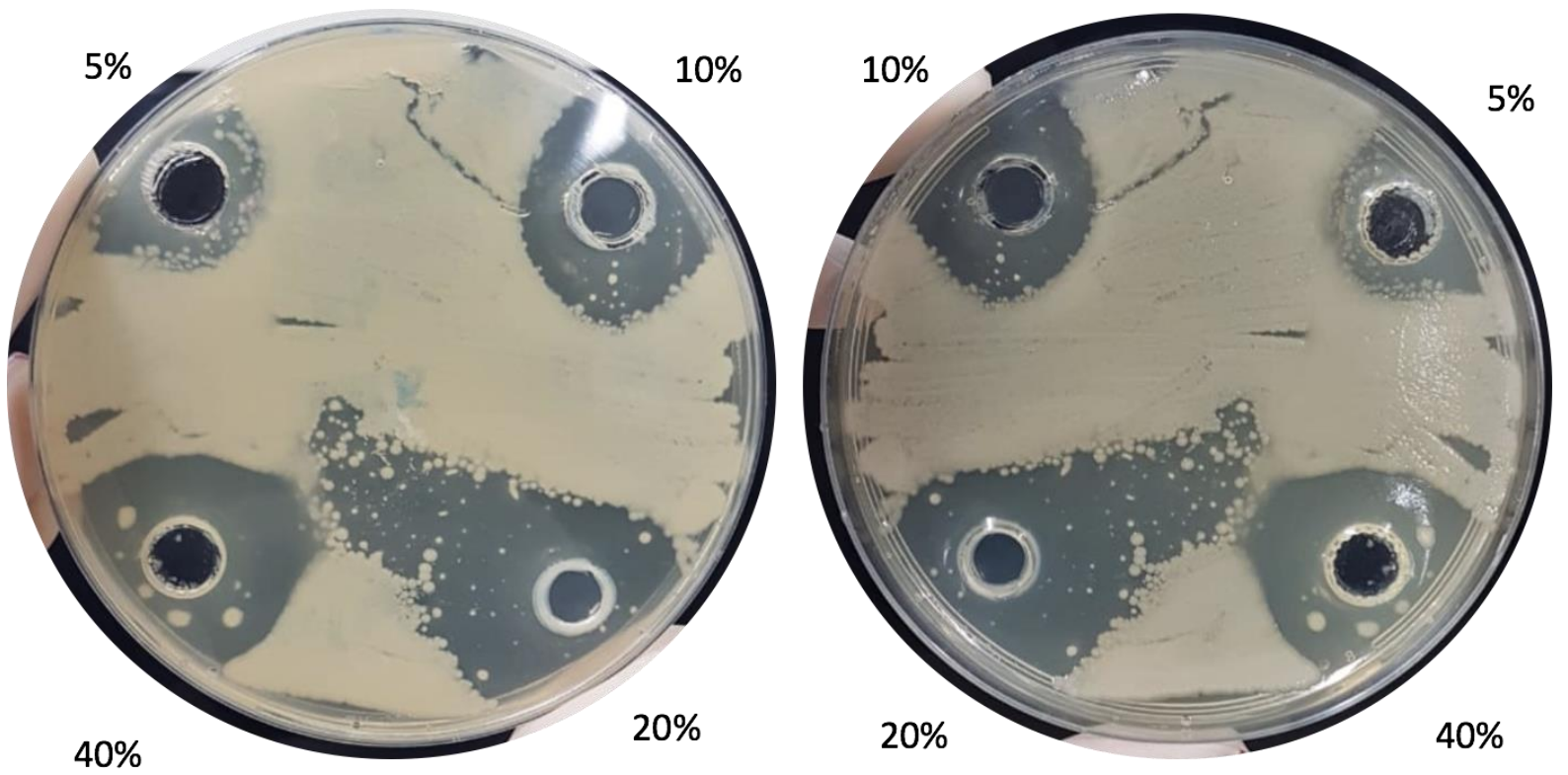


Figura 5: Halos de inibição da cepa de $B$. thuringiensis frente ao óleo essencial de laranja em ágar Mueller Hinton.
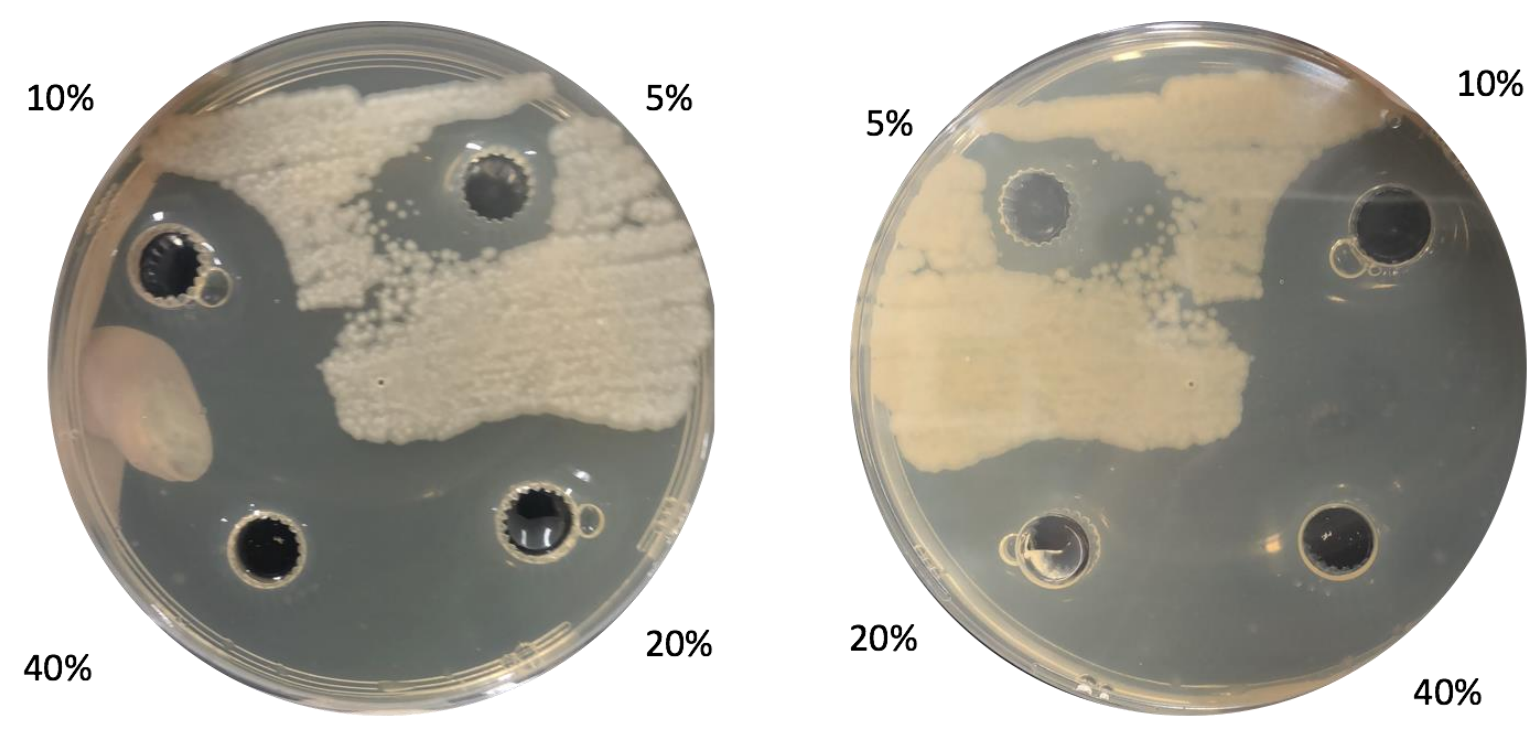

Figura 6: Halos de inibição da cepa de $B$. thuringiensis frente ao óleo essencial de limão em ágar Mueller Hinton.
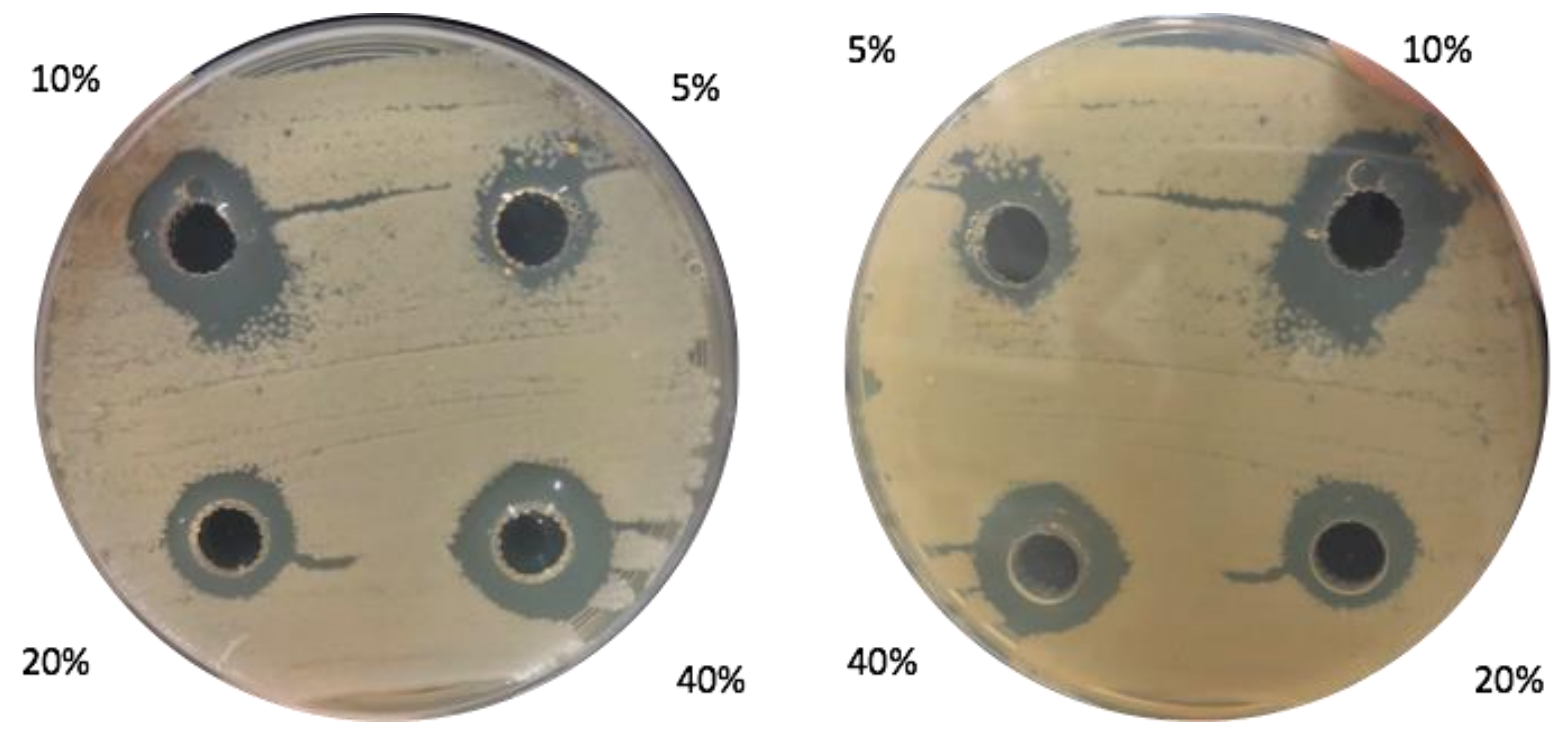
Figura 7: Halos de inibição da cepa de $S$. aureus frente ao óleo essencial de cravo em ágar Mueller Hinton.
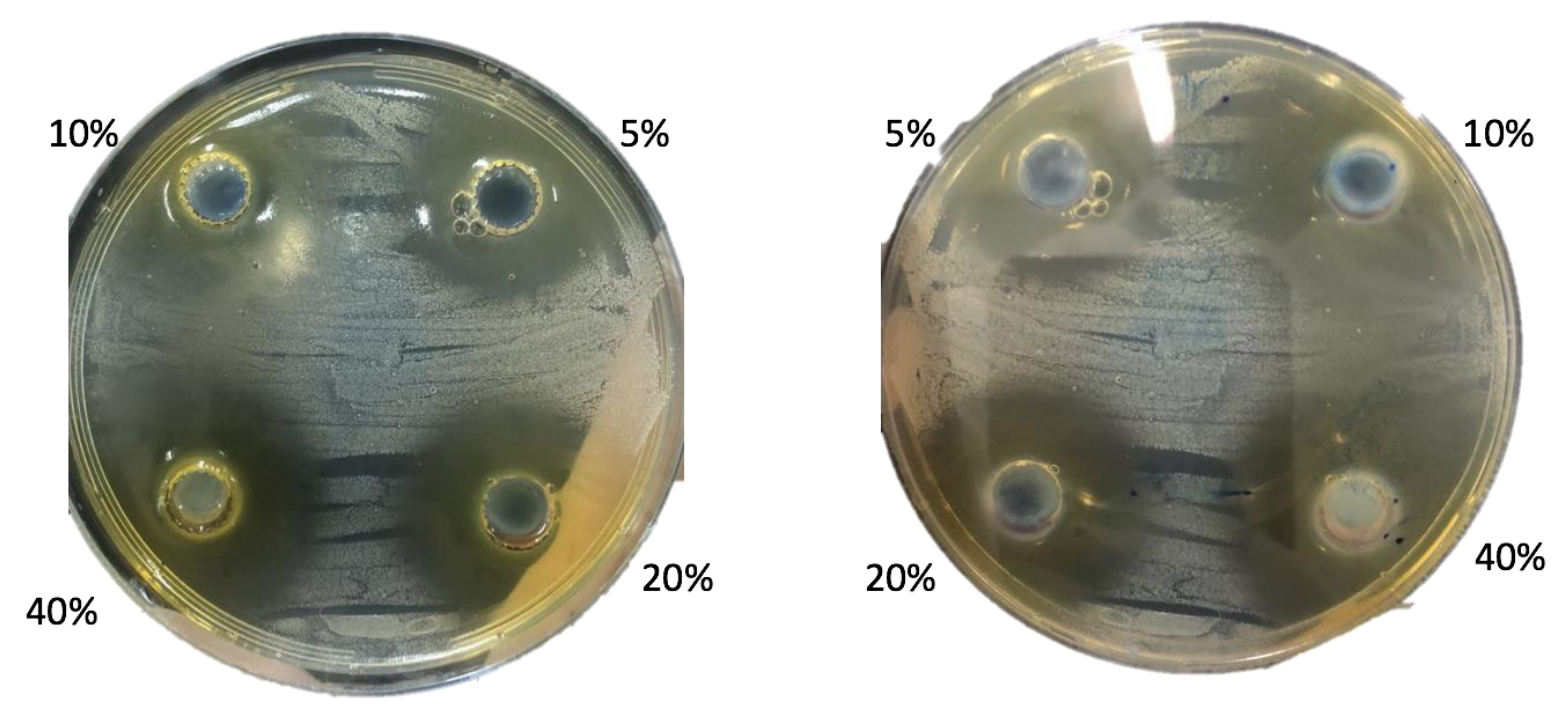

Figura 8: Halos de inibição da cepa de $E$. coli frente ao óleo essencial de cravo em ágar Mueller Hinton.
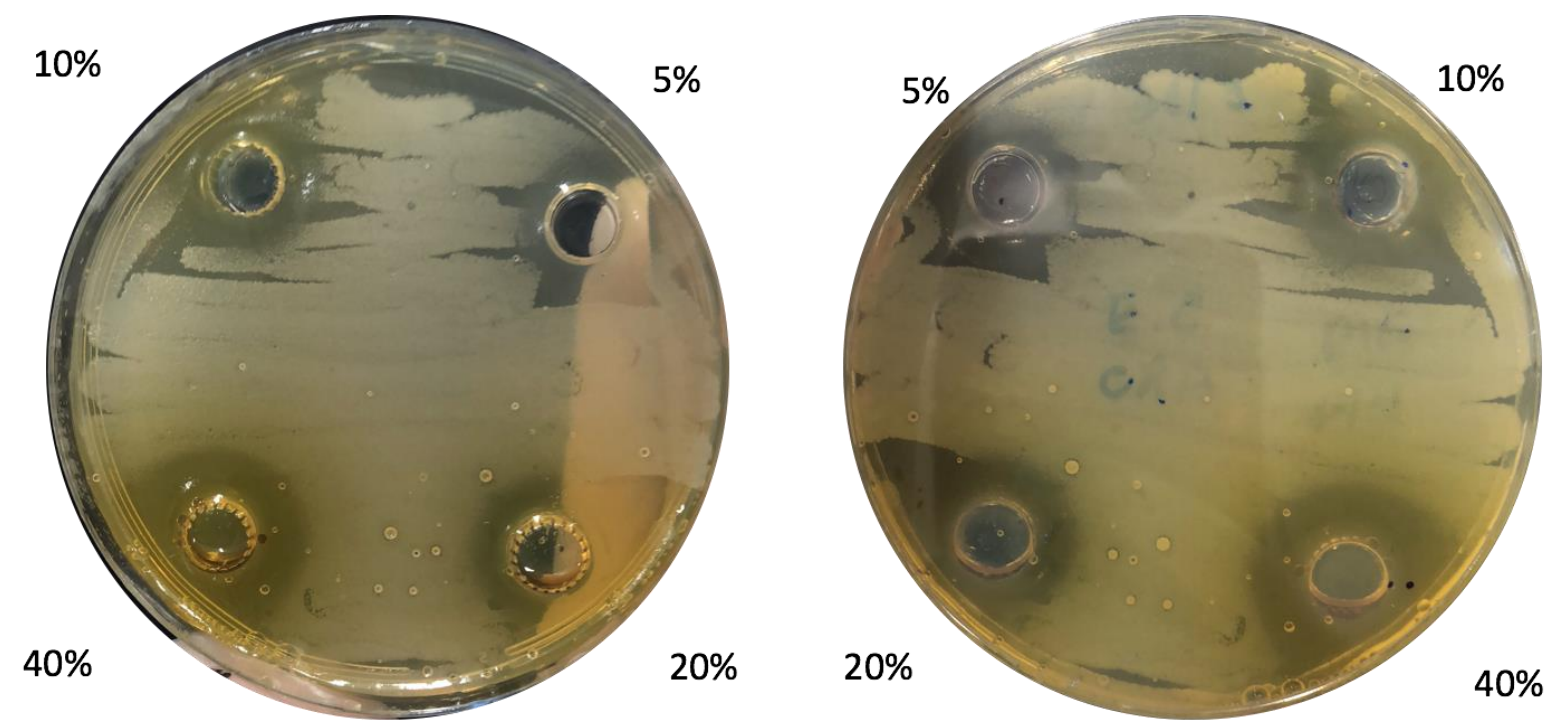
Figura 9: Halos de inibição da cepa de S. aureus frente ao óleo essencial de canela em ágar Mueller Hinton.
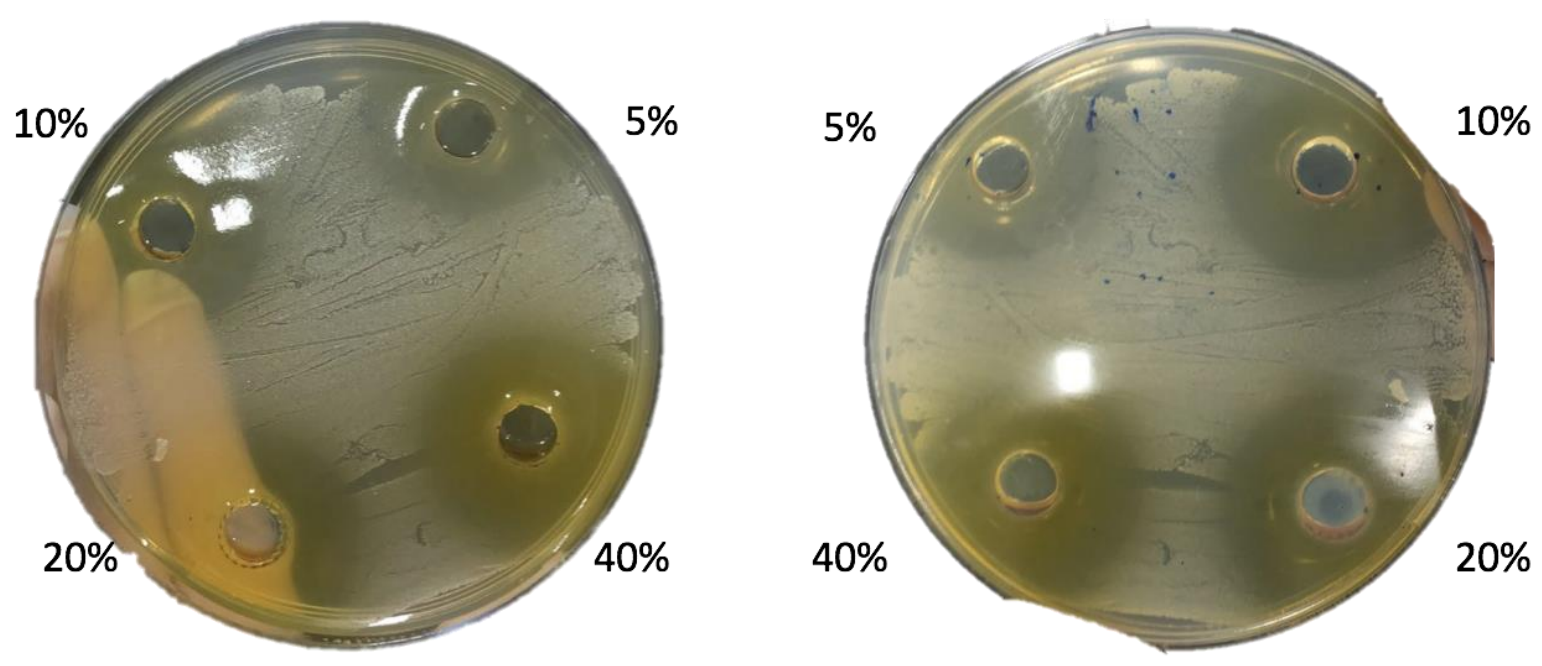

Figura 10: Halos de inibição da cepa de K. pneumoniae frente ao óleo essencial de lavanda em ágar Mueller Hinton.
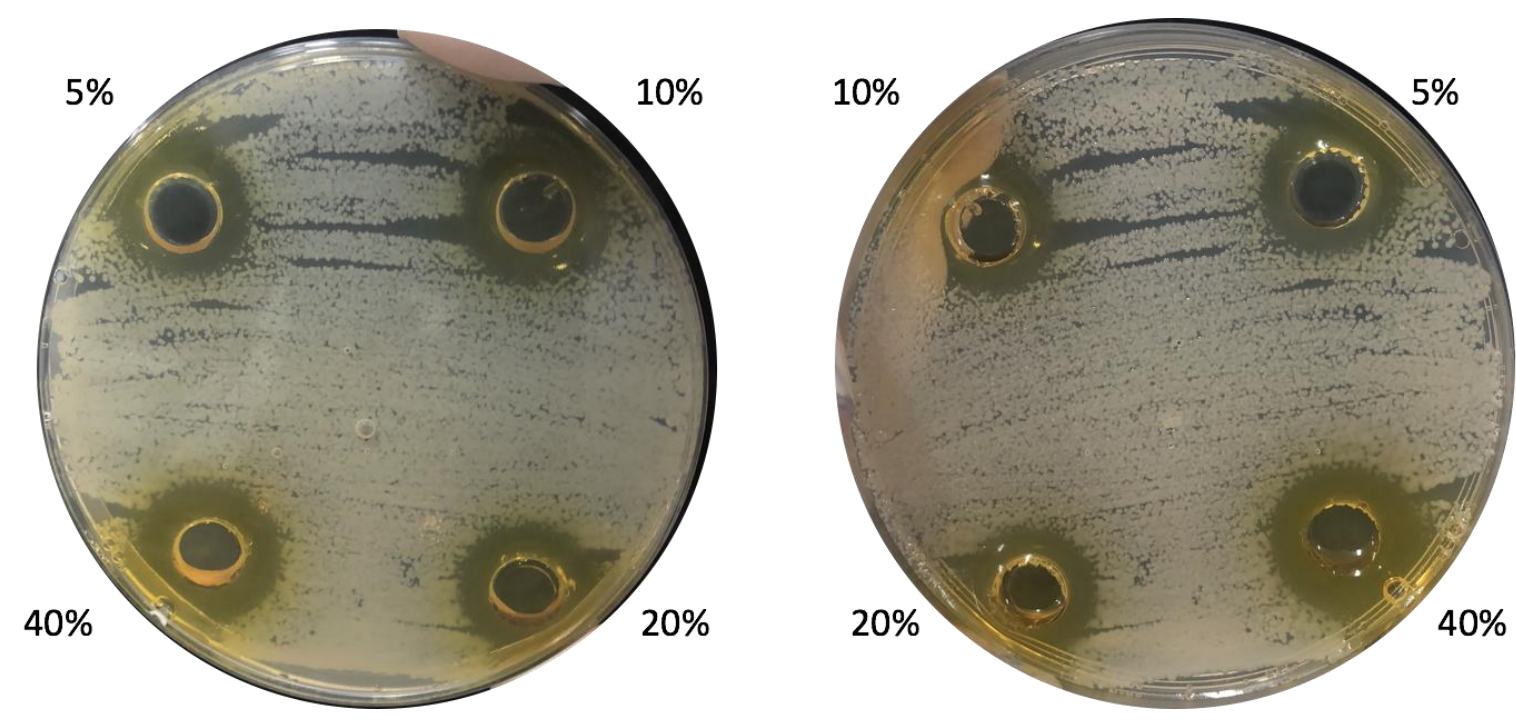
Nos testes em difusão em ágar foram utilizadas as concentrações iniciando a partir de $5 \%$. Não se utilizou a concentração de $2,5 \%$ como nos ensaios em placas de ELISA devido a capacidade máxima de apenas 4 poços por placas. Número de poços além de 4 poderiam gerar resultados discrepantes.

Observa-se que nas tabelas 1 a 5 e também nas figuras de 1 a 10 que os óleos testados são classificados como muito ativos e que as cepas de bactérias Gram positivas foram mais inibidas do que as cepas de bactérias Gram negativas. Em alguns casos não houve o crescimento bacteriano esperado devido a instabilidade de crescimento da bactéria que foi repicada. Os óleos essenciais a base de citronela, hortelã e pimenta rosa não foram capazes de inibir nenhuma bactéria testada, resultado discrepante em relação a outra pesquisa realizada por Carvalho e colaboradores (2017), onde mesmo que apresentando halos pequenos, o óleo essencial a base de pimenta rosa foi capaz de inibir cepas de $S$. aureus e $E$. coli.

Diferentes atividades antimicrobianas entre os óleos podem ter ocorrido devido às diferentes composições de cada um, nos diluentes utilizados, na concentração de células microbianas e na cultura de referência (ANDRADE et al. 2012). O bom resultado dos óleos essenciais na presente pesquisa deve-se às suas composições químicas, principalmente dos óleos que apresentam eugenol e limoneno, encontrados nos óleos essenciais de laranja e canela, componentes os quais apresentam atividade antimicrobiana comprovada na literatura (SANTOS JÚNIOR, 2012).

De acordo com os resultados obtidos, pode-se concluir que a cepa de $P$. aeruginosa apresentou resistência a quatro dos 10 óleos essenciais testados, sendo considerada a bactéria mais resistente. Já S. aureus foi considerada a cepa mais susceptível a ação dos óleos essenciais, um dado interessante frente a grande importância desta bactéria em infecções causadas por biofilmes.

A eficácia desses óleos em conseguir inibir o crescimento bacteriano possibilita que estes sejam utilizados como uma forma alternativa aos antimicrobianos, tanto na indústria alimentícia, como na área da saúde. Tendo isso em vista é necessário descobrir qual a concentração que os OE's devem ser utilizados, que se da através de testes in vitro que consigam determinar a menor concentração que tenha efeito bacteriostático ou inibitório, definindo assim a concentração mínima inibitória (CMI) (BURT, 2004). 
Após os ensaios usando os óleos vegetais que foram adicionados em meio ágar Mueller-Hinton, realizou-se os ensaios em placas de Elisa para a medição das absorbâncias visando determinar o efeito dos óleos vegetais em inibir o crescimento dos microrganismos (Figura 11).

A leitura espectrofotométrica foi capaz de determinar o efeito dos extratos no crescimento das bactérias. No ensaio com óleo de laranja observou-se que em baixas concentrações do extrato foi possível ver o efeito inibitório a partir de baixas concentrações dos óleos. Esse efeito foi medido a partir da concentração da 2,5\%. No ensaio com óleo de laranja foi possível ver a inibição do crescimento em todas as bactérias testadas.

Nos óleos de canela e limão apresentaram efeito inibitório intermediário no crescimento das bactérias testadas.

Já os extratos de hortelã, gengibre e pimenta rosa foram menos efetivos em inibir o crescimento das bactérias utilizadas nesse estudo.

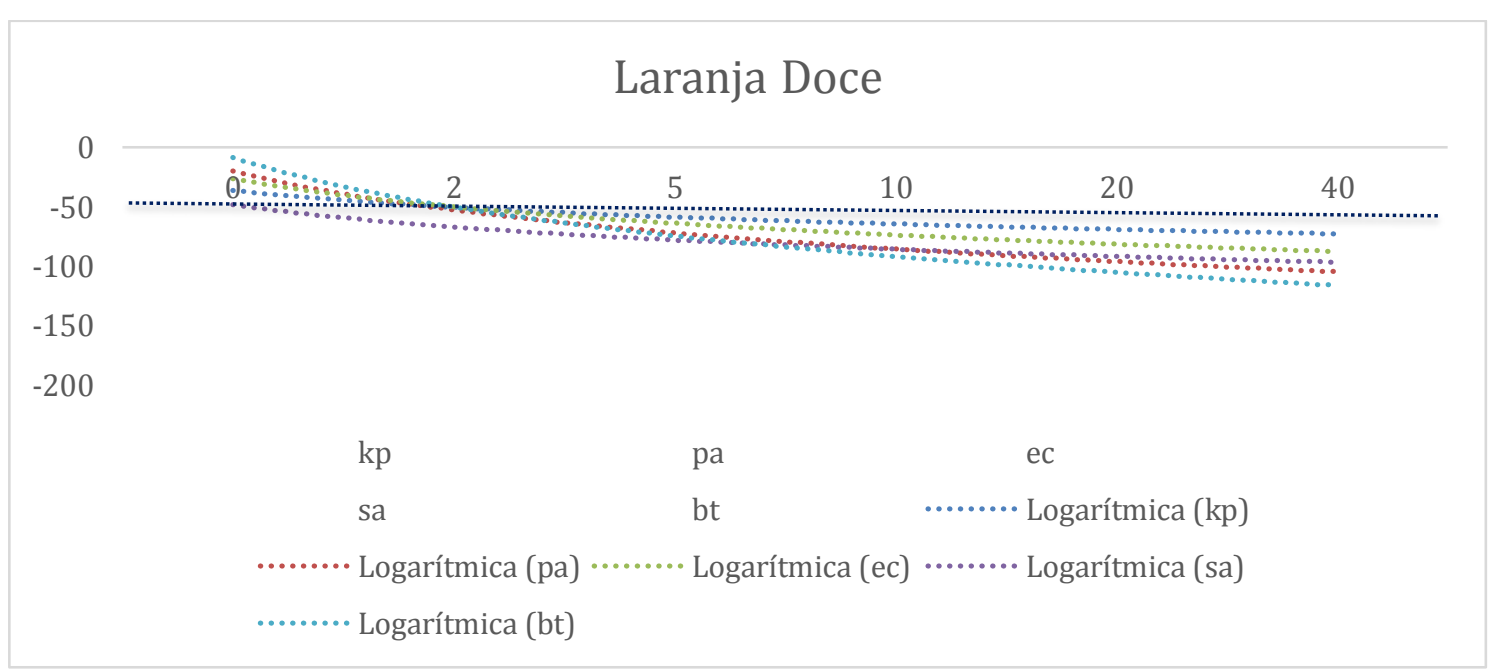




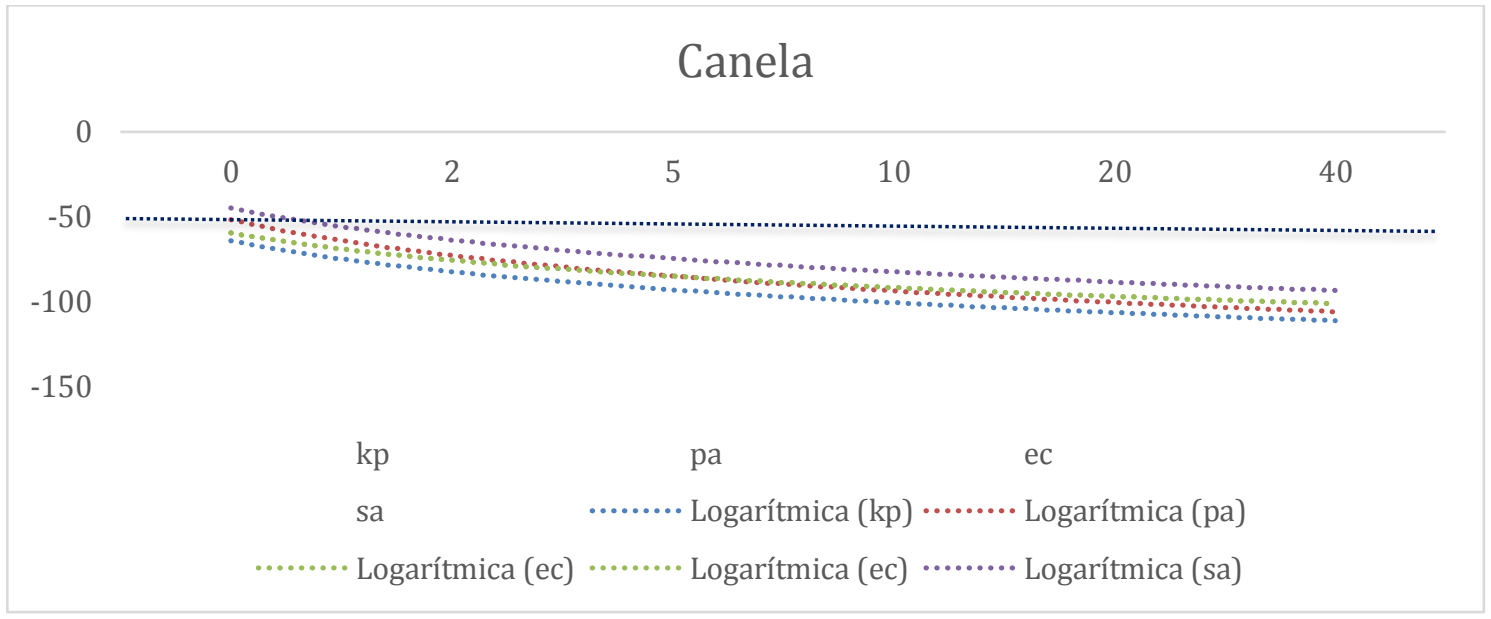

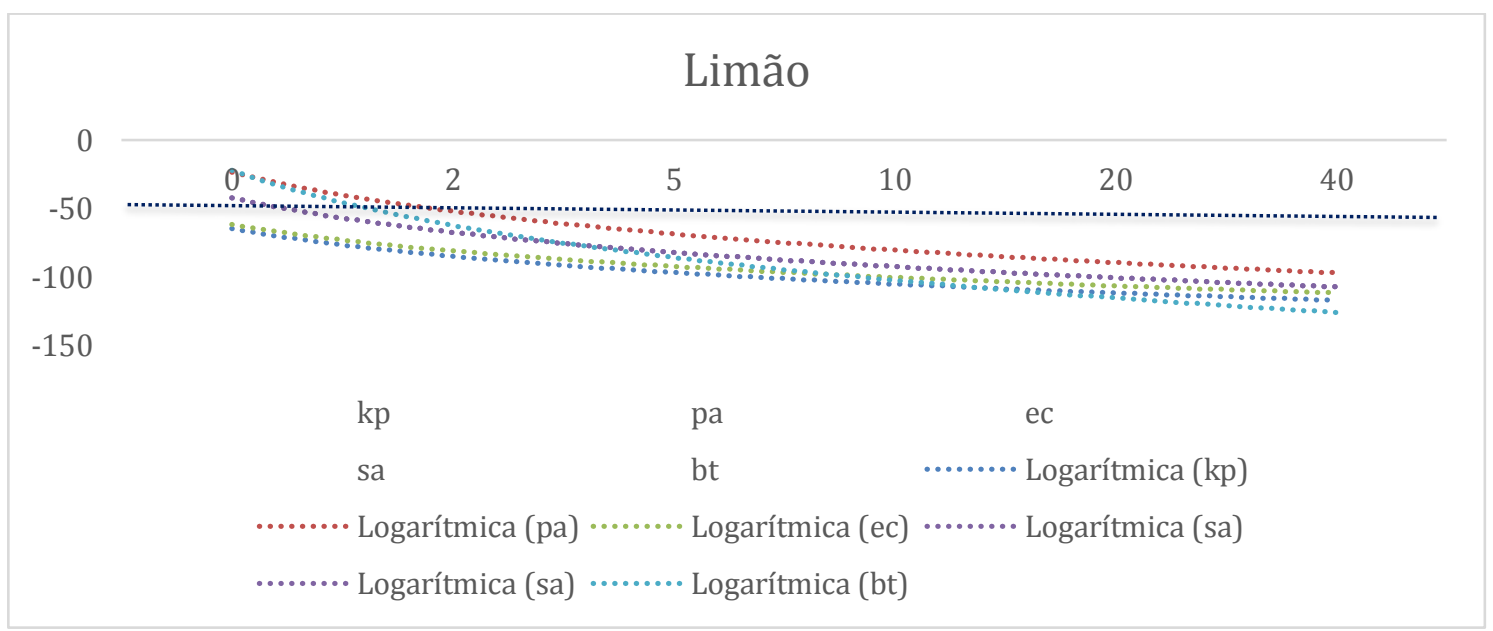

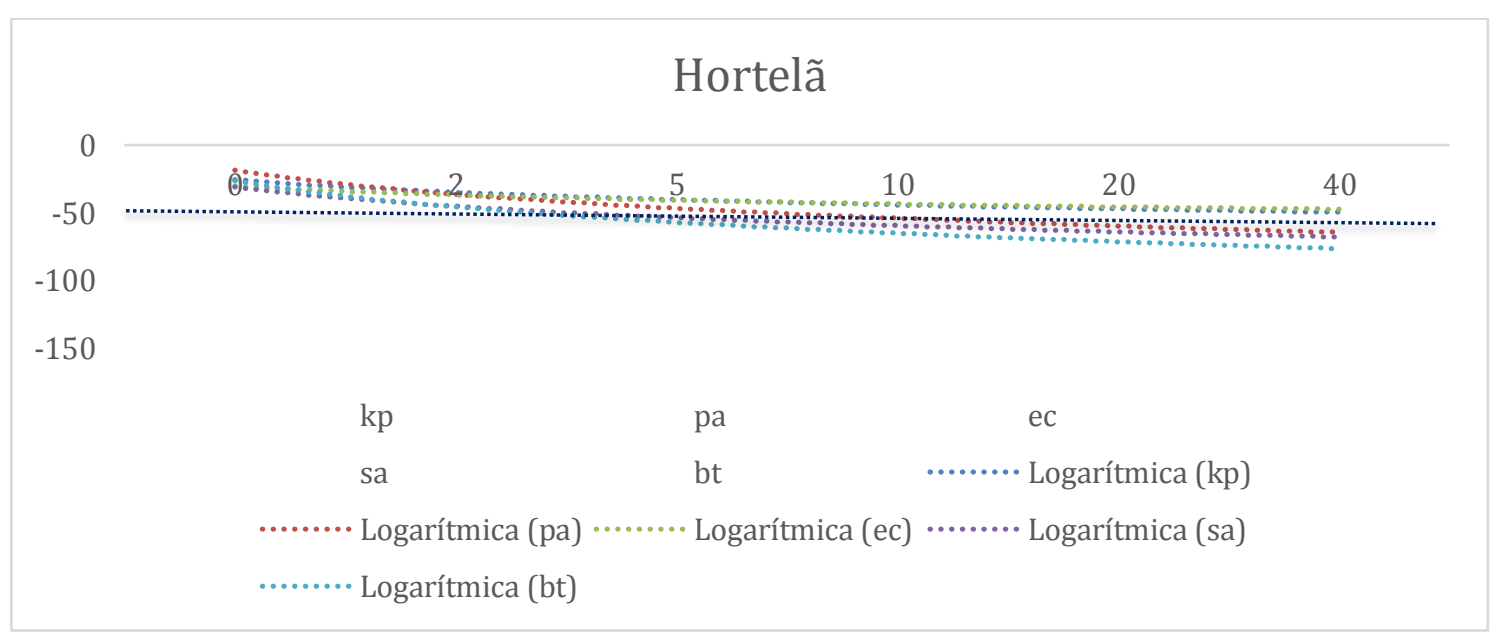



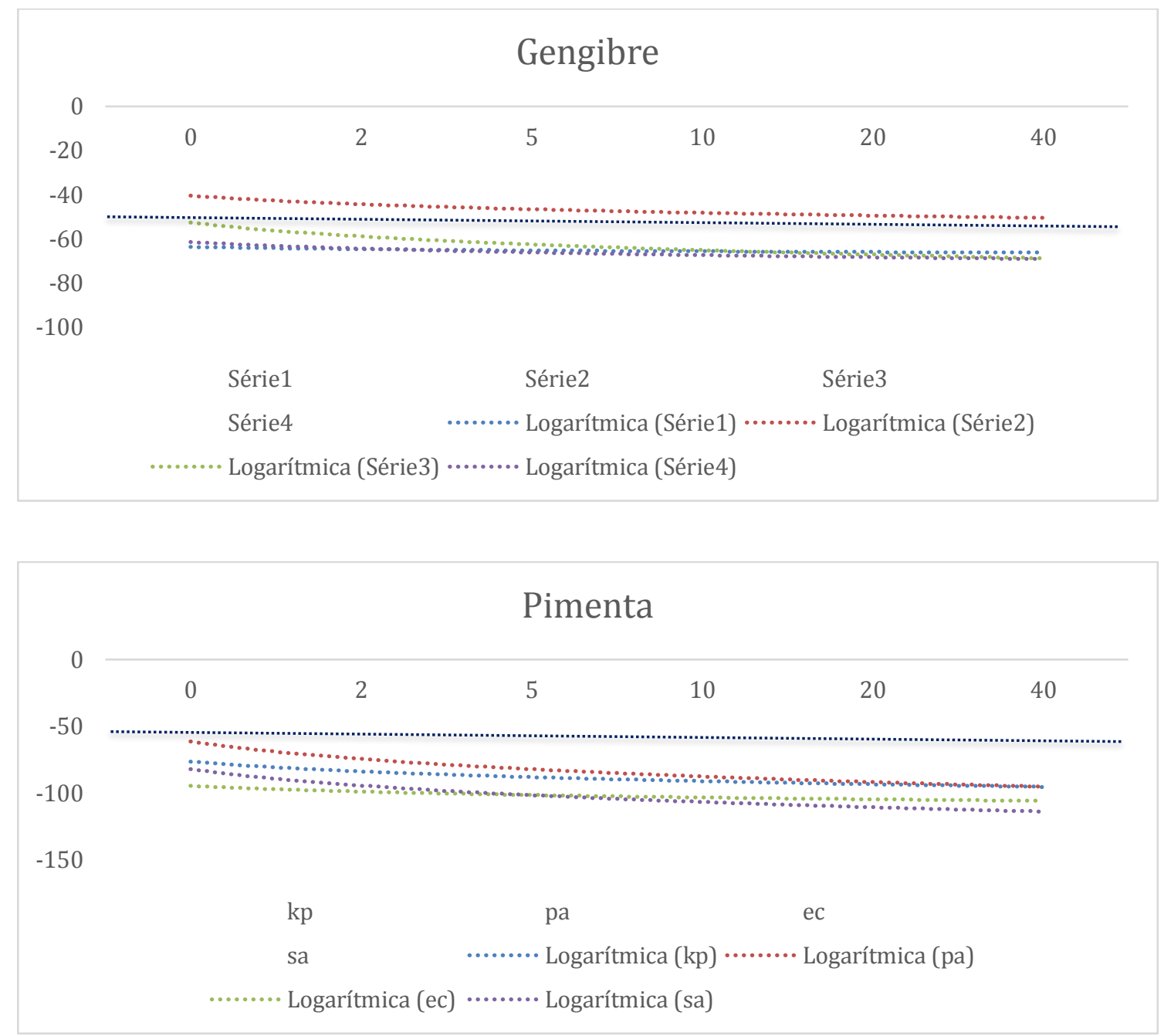

Figura 11 - Gráficos da medida espectrofotométrica do efeito inibitório dos óleos vegetais no crescimento das bactérias $P$. aeruginosa, $S$. aureus, $K$. pneumoniae, $E$. coli e $B$. thuringiensis. $O$ extrato de laranja produziu a inclinação mais abrupta na concentração de $2,5 \%$. Os óleos de canela e limão produziram inclinações de curva menos acentuadas no crescimento das bactérias testadas. Os óleos de hortelã, gengibre e pimenta não produziram inclinações sensíveis no crescimento das bactérias. A linha pontilhada indica o efeito inibitório de $50 \%$ no crescimento bacteriano.

Segundo Stepanovic e colaboradores (2007), medidas espectofotométricas são importantes para aumentar a precisão dos resultados obtidos através de cálculos que irão determinar a concentração mínima inibitória dos óleos essenciais utilizados. Estes cálculos são importantes pois separam as cepas que foram capazes de formar biofilme das demais que não formaram biofilme. 
Após as determinações dos testes do potencial inibitório dos extratos vegetais tanto em ágar quanto em placa de Elisa, realizou-se o teste em placa de Elisa para a detecção do biofilme formado nas bactérias testadas (Figura 12).

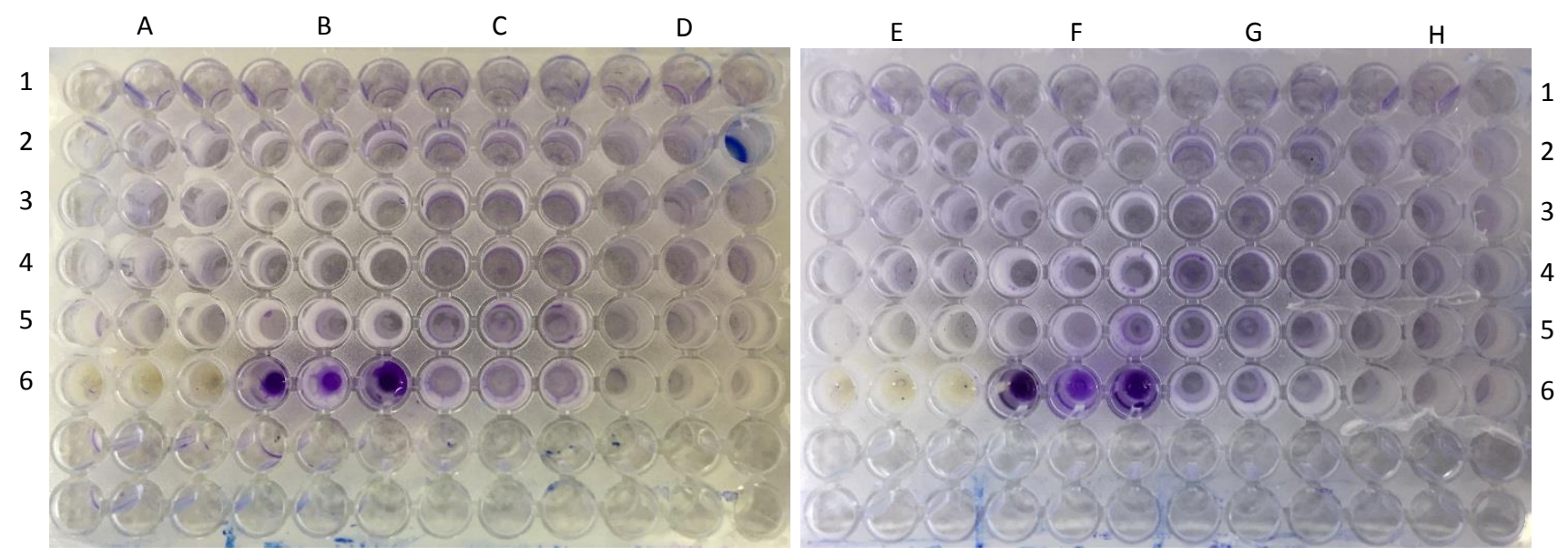

Figura 12 - Detecção do biofilme utilizando os extratos contra as bactérias $P$. aeruginosa, $S$. aureus $e$ B. thuringiensis. Em A, B. thuringiensis com óleo essencial de laranja; $\mathbf{B}, \mathbf{B}$. thuringiensis com óleo essencial de eucalipto; $C, B$. thuringiensis com óleo essencial de hortelã; D, P. aeruginosa com óleo essencial de gengibre; E, S. aureus com óleo essencial de laranja; F, S. aureus com óleo essencial de eucalipto; G, S. aureus com óleo essencial de hortelã; H, $P$. aeruginosa com óleo essencial de gengibre. As concentrações dos extratos são indicadas pelos números: 1 , Controle sem extrato; $2,2,5 \% ; 3,5 \% ; 4,10 \% ; 5,20 \% ; 6,40 \%$.

Utilizando-se a técnica de coloração, observou-se que o corante cristal violeta ficou visível apenas nas amostras com maior concentração de extrato. A partir da menor concentração do extrato observa-se um leve tom azul-roxo indicando que os extratos impactaram na formação dos biofilmes bacterianos.

Ressalta-se que essa técnica de coloração só é efetiva contra as bactérias Gram positivas e que algumas cepas de bactérias somente produzem biofilmes em placas contendo meio de cultura, e na presente pesquisa foi utilizada solução salina no lugar de BHI, fato o qual pode explicar a falta de coloração nos poços de controle sem extrato, o qual deveria ser observado o corante de cristal de violeta de forma marcante (STEPANOVIC et al., 2007). 


\section{CONSIDERAÇÕES FINAIS}

Os resultados obtidos indicaram que baixas concentrações dos extratos de laranja doce e eucalipto foram efetivas em inibir bactérias as Gram positivas (S. aureus e $B$. thuringiensis) e negativas (E. coli, P. aeruginosa e K. pneumoniae) utilizadas nesse estudo dentro de $24 \mathrm{~h}$ de ensaio. Além disso, algumas bactérias foram mais inibidas (S. aureus e $K$. pnuemoniae) do que outras (P. aeruginosa e B. thuringiensis) indicando que os extratos exercem efeitos diferentes entre as bactérias testadas. Os resultados sugerem que os componentes presentes nos extratos vegetais podem exercem um efeito importante na formação dos biofilmes indicando uma possibilidade de uso alternativo e complementar desses compostos no controle microbiano.

\section{REFERÊNCIAS}

AAWC (Association for the Advancement of Wound Care). Advancing your practice: Understanding Wound Infection and the Role of Biofilms. Malvern: AAWC. 2008.

ANDRADE, M. A. et al. Óleos essenciais de Cymbopogon nardus, Cinnamomum zeylanicum e Zingiber officinale: composição, atividades antioxidante e antibacteriana. Revista Ciência Agronômica, Fortaleza, v. 43, n. 2, 2012.

AUGER, S. et al. Biofilm Formation and Cell Surface Properties among Pathogenic and Nonpathogenic Strains of the Bacillus cereus Group. Applied and Environmental Microbiology, Washington, v. 75, n. 20, p. 6616-6618, 2009.

BALESTRINO, D. et al. Characterization of Type 2 Quorum Sensing in Klebsiella pneumoniae and Relationship with Biofilm Formation. Journal of Bacteriology, Washington, v. 187, n. 8, p. 2870-2880, 2005.

BARROS, M. P. Venenos como fonte de moléculas ativas contra biofilmes bacterianos patogênicos. 2017. 212f. Tese/Dissertação apresentada ao Programa de Pós-Graduação em Ciências Farmacêuticas, em nível de Doutorado/Mestrado Acadêmico da Faculdade de Farmácia da Universidade Federal do Rio Grande do Sul, Porto Alegre, 2017.

BERTINI, M. L. Perfil de Sensibilidade de Bactérias Frente A Óleos Essenciais de Algumas Plantas do Nordeste do Brasil. Infarma, Fortaleza, v. 17, n³/4, p. 80-83, 2005. 
BLASSER, L. Bonnie. Small Talk: Cell-To-Cell Communication In Bacteria. Cell, Cambridge, v. 109, n. 4, p. 421-424, 2002.

BLASSER, B. How Bacteria Talk to Each Other: regulation of Gene expression by quorum sensing. Current Opinion in Microbiology, England, v. 2, p. 582-587, 1999.

BOARI, A. C. et al. Formação de biofilme em aço inoxidável por Aeromonas hydrophila e Staphylococcus aureus usando leite e diferentes condições de cultivo. Ciência e Tecnologia de Alimentos, Campinas, v. 29, n. 4, p. 886-895, 2009.

BOSCARIOL, R; OUCHI, J. D; PEREIRA, G. C. Produção de biofilme por Staphylococcus aureus. Revista Saúde em Foco, Amparo, v. 10, 2018.

BURT, S. Essential oils: their antibacterial properties and potential applications in foods-a review. International Journal of Food Microbiology, Holanda, v. 94, n. 3, p. 223-253, 2004.

CARVALHO, I. O. Atividade antimicrobiana de óleos essenciais e cremes fitoterápicos com bactérias cariogênicas. 2016. 102f. Dissertação (mestrado) - Universidade Federal de Viçosa, Viçosa, 2016.

CARVALHO, J. A. M. et al. Composição química e avaliação da atividade antimicrobiana do óleo de pimenta rosa (Schinus terebinthifolius). Blucher Chemical Engineering Procedures, São Paulo, v. 4, n. 1, p. 59-63, 2017.

CASTRO, H. G. et al. Avaliação do teor e composição do óleo essencial de Cymbopogon nardus (L.) em diferentes épocas de colheita. Revista Ciência Agronômica, Fortaleza, v. 41, n. 2, p. 308-314, 2010.

CHEN, X. et al. Structural Identification of a Bacterial Quorum Sensing Signal Containing Boron. Nature, Hawthorne, v. 415, p. 545-549, 2002.

CHILDERS, B. M. et al. MrkD1p from Klebsiella pneumoniae Strain IA565 Allows for Coexistence with Pseudomonas aeruginosa and Protection from Pretease-Mediated Biofilm Detatchment. Infection and Imunology, Bethesda, v. 81, n. 11, p. 4112-4120, 2013.

CONCEIÇÃO, R. A. Formação de biofilme em amostras de Escherichia coli associada a sepse (SEPEC): caracterização fenotípica, genotípica e filogenia. 2010. 66f. Dissertação (Mestrado) em Genética e Biologia Molecular do Instituto de Biologia da Universidade Estadual de Campinas, Campinas, 2010.

DE KIEVIT, T. R. Quorum sensing in Pseudomonas aeruginosa biofilms. Environmental Microbiology, Oxford, v. 11, n. 2, p. 279-88, 2009. 
DONLAN, R.M. Biofilm Formation: A Clinically Relevant Microbiological Process. Infectious Diseases Society of America, Chicago, v. 33, n. 8, p. 1387-1392, 2001.

DORMAN, H. J; DEANS, S. G. Antimicrobial agents from plants: antibacterial activity of plants volatile oils. Journal of Applied Microbiology, Inglaterra, v. 88, n. 2, p. 308-316, 2000.

FEDERLE, M. J; BLASSER, B. L. Interspecies Communication in Bacteria. The Journal of Clinical Investigation, New Haven, v. 112, n. 9, p. 1291-1299, 2003.

GREENBERG, E. P. Bacterial communication: Tiny Teamwork. Nature, Londres, v. 424, n. 6945, p. 134, 2003.

GONDIM, B. L. et al. Atividade Antimicrobiana de Produtos Naturais Frente a Bactérias Formadoras do Biofilme Dentário. Pesquisa Brasileira em Odontopediatria e Clínica Integrada, vol 11, n. 11, núm 1, p. 123-127, 2011.

GONZÁLEZ-BARRIOS, A.F. et al. Autoinducer 2 controls biofilm formation in Escherichia coli through a novel motility quorum-sensing regulator (MqsR, B30022). Journal of Bacteriology, Washington, v. 188, n. 1, p. 305-316, 2006.

HALL-STOODLEY, L. et al. Bacterial Biofilms: From the Natural Environment to Infectious Diseases. Nature Reviews: Microbiology, Londres, v. 2, n.2, p. 95-108, 2004.

INOUE, F. A. Avaliação de atividades biológicas e estudo fitoquímico de extratos de flores de Senna marcranthera. 2006. 86f. Dissertação (mestrado)- Universidade Federal de Viçosa, Viçosa, 2006.

JAYARAMAN, A; WOOD, T.K. Bacterial Quorum Sensing: Signals, Circuits, and Implications for Biofilms and Disease. Annual Review of Biomedical Engineering, Polo Alto, v. 10, p. 145-167, 2008.

KALEMBA, D.; KUNICKA, A. Antibacterial and antifungal properties of essential oils. Current Medicinal Chemistry, Emirados Árabes, v.10, n.10, p.813-29, 2003.

KASNOWSKI, M. C. et al. Formação de Biofilme na Indústria de Alimentos e Métodos de Validação de Superfícies. Revista Científica Eletrônica de Medicina Veterinária, São Paulo, n.15, 2010.

KELLER, L; SURETTE, M.G. Communication in bacteria: an ecological and evolutionary perspective. Nature Reviews Microbiology, Londres, v. 4, n.4, p. 249-258, abr. 2006. 
$\mathrm{KOH}$, C. et al. Plant-Derived Natural Products as Sources of Anti-Quourum Sensing Compounds. Sensors, Basel, v. 13, n. 5, p. 6217-6228, 2013.

NAZZARO, F. et al. Effect os Essential Oils on Pathogenic Bacteria. Pharmaceuticals, Italia, v. 6, p. 1451-1474, 2013.

MILLER, M; BLASSER, B. Quorum Sensing in Bacteria. Annual Review of Microbiology, Polo Alto, v. 55, p. 165-199, 2001.

MILLEZI, A. F. Ação de óleos essenciais sobre biofilmes formados por Staphylococcus aureus e Escherichia coli. 2012. 113 f. Tese (Doutorado) do Programa de Pós-Graduação em Microbiologia Agrícola da Universidade Federal de Lavras, Lavras, 2012.

MISHARINA, T. A; SAMUSENKO, A. L. Antioxidant properties of essential oils from lemon, grapefruit, coriander, clove, and their mixtures. Applied Biochemistry and Microbiology, Russia, v. 45, n. 4, p. 438-442, 2008.

MOTHANA, R. A; LINDEQUIST, U. Antimicrobial activity of some medicinal plants of the island Soqotra. Journal of Ethnopharmacology, Irlanda, v. 96, n. 1-2, p. 177-181, 2005.

MUHS, A. et al. Virulence Inhibitors from Brazilian Peppertree Block Quorum Sensing and Abate Dermonecrosis in Skin Infection Models. Scientific Reports, Londres, v.7, p. 1-15, 2017.

NAZARRO, F. et al. Effect of Essential Oils on Pathogenic Bacteria. Pharmaceuticals, Basel, v. 6, n. 12, p. 1451-1474, 2013.

PARSEK, M.R; GREENBERG, P. E. Sociomicrobiology: The Connections Between Quorum Sensing and Biofilms. Trends in Microbiology, Cambridge, v.13, n. 1, p. 27-33, 2005.

RUMJANEK, N. G. et al. Quorum Sensing em Sistemas Agrícolas: comportamento multicelular em procariotos via comunicação intracelular Revista Biotecnologia Ciência \& Desenvolvimento, Belo Horizonte, v. 33, p. 35-50, 2004.

SANTOS JÚNIOR, A. C. Ação de óleos essenciais sobre biofilmes formados por Staphylococcus aureus e Escherichia coli. 2012. 112f. Tese (doutorado) para Universidade Federal de Lavras, Lavras, 2012.

SATO, H. et al. The mechanism of action of the Pseudomonas aeruginosa-encoded type III cytotoxin, ExoU. The EMBO Journal, Eynsham, v. 22, n. 12, p. 2959-2969, 2003. 
SCHAUDER, S; BASSLER, B. The languages of bacteria. Genes \& Development, Cold Spring Harbor v. 15, n. 12, p. 1468-1480, 2001.

SCHUCK, V. J. A. et al. Avaliação da atividade antimicrobiana de Cymbopogon citratus. Revista Brasileira de Ciências Farmacêuticas, São Paulo, v. 37, n. 1, 2001.

SILVEIRA, S. M. et al. Composição e atividades antibacterianas dos óleos essenciais de Cymbopogon winterianus (citronela), Eucalyptus paniculata (eucalipto) e Lavandula angustifolia (lavanda). Revista do Instituto Adolfo Lutz, São Paulo, v. 71, n. 3, p. 471-480, 2012.

SOLA, M. C. et al. Mecanismos de Quorum Sensing e sua relevância na microbiologia de alimentos. Enciclopédica Biosfera, Goiânia, v. 8, n. 14, p. 1419-144, 2012.

SOUSA, C. Segurança Alimentar e Doenças Veiculadas Por Alimentos: Utilização do Grupo Coliforme como um Dos Indicadores de Qualidade de Alimentos. Revista APS, Juiz de Fora, v. 9, n.1, p. 83-88, 2006.

SOUZA, Yasmin; et al. SUPERBACTÉRIAS: UM PROBLEMA EMERGENTE. Faculdade Alfredo Nasser - Instituto de Ciências da Saúde. $4^{\circ}$ Seminário Pesquisar. Dez 2015.

TOMAZZONI, M. et al. Fitoterapia Popular: A Busca Instrumental Enquanto Prática Terapêutica. Texto \& Contexto Enfermagem, Santa Catarina, v. 15, n. 1, p. 115-121, 2006.

VAN LEEUWEN, W. et al. Population Studies of Methicillin-Resistant and -Sensitive Staphylococcus aureus Strains Reveal a Lack of Variability in the agrD Gene, Encoding a Staphylococcal Autoinducer Peptide. Journal of Bacteriology, Nova York, v.182, n.20, p. 57215729, 2000.

VIANA, E. Moléculas Sinalizadoras de Quorum sensing em Biofilmes Formados por Bactérias Psicrotróficas Isoladas de Leite. 2006. 176f. Dissertação (Mestrado em Microbiologia Agrícola) - Universidade Federal de Viçosa, Viçosa, MG. 2006.

WATERS, C; BLASSER, B. Quorum sensing: Cell-to-Cell Communication in Bacteria. Annual Review of Cell and Developmental Biology, Polo Alto, v. 21, p. 319-346, 2005.

WHITCHURCH, C. B. et al. Extracellular Required for Bacterial Biofilm Formation. Science, Nova York, v. 295, n. 5559, p. 1487, 2002 